\title{
Article \\ Comparative Analysis Based on Transcriptomics and Metabolomics Data Reveal Differences between Emmer and Durum Wheat in Response to Nitrogen Starvation
}

\author{
Romina Beleggia ${ }^{1}\left(\mathbb{D}\right.$, Nooshin Omranian ${ }^{2,3}$, Yan Holtz ${ }^{4}$, Tania Gioia ${ }^{5} \mathbb{D}_{\text {, Fabio Fiorani }}{ }^{6}$, Franca M. Nigro ${ }^{1}$, \\ Nicola Pecchioni ${ }^{1}$, Pasquale De Vita ${ }^{1}$ (D), Ulrich Schurr ${ }^{6}$, Jacques L. David ${ }^{4}$, Zoran Nikoloski ${ }^{2,3,7}$ \\ and Roberto Papa $1,8, * \mathbb{D}$
}

Citation: Beleggia, R.; Omranian, N.; Holtz, Y.; Gioia, T.; Fiorani, F.; Nigro, F.M.; Pecchioni, N.; De Vita, P.; Schurr, U.; David, J.L.; et al. Comparative Analysis Based on Transcriptomics and Metabolomics Data Reveal Differences between Emmer and Durum Wheat in Response to Nitrogen Starvation. Int. J. Mol. Sci. 2021, 22, 4790. https://doi.org/ $10.3390 /$ ijms 22094790

Academic Editor: Massimo Maffei

Received: 19 March 2021

Accepted: 28 April 2021

Published: 30 April 2021

Publisher's Note: MDPI stays neutral with regard to jurisdictional claims in published maps and institutional affiliations.

Copyright: (C) 2021 by the authors. Licensee MDPI, Basel, Switzerland. This article is an open access article distributed under the terms and conditions of the Creative Commons Attribution (CC BY) license (https:/ / creativecommons.org/licenses/by/ $4.0 /)$.
1 Council for Agricultural Research and Economics (CREA), Research Centre for Cereal and Industrial Crops (CREA-CI), 71122 Foggia, Italy; romina.beleggia@crea.gov.it (R.B.); franks22@libero.it (F.M.N.); nicola.pecchioni@crea.gov.it (N.P.); pasquale.devita@crea.gov.it (P.D.V.)

2 Systems Biology and Mathematical Modeling Group, Max Planck Institute of Molecular Plant Physiology, 14476 Potsdam, Germany; omranian@mpimp-golm.mpg.de (N.O.); Nikoloski@mpimp-golm.mpg.de (Z.N.)

3 Bioinformatics, Institute of Biochemistry and Biology, University of Potsdam, 14476 Potsdam, Germany

4 Montpellier SupAgro, UMR Amelioration Genetique et Adaptation des Plantes, 34060 Montpellier, France; yan.holtz.data@gmail.com (Y.H.); jacques.david@supagro.fr (J.L.D.)

5 Scuola di Scienze Agrarie, Forestali, Alimentari e Ambientali, Università degli Studi della Basilicata, 85100 Potenza, Italy; tania.gioia@unibas.it

6 Institute of Biosciences and Geosciences (IBG-2): Plant Sciences, Forschungszentrum Julich GmbH, 52428 Julich, Germany; f.fiorani@fz-juelich.de (F.F.); u.schurr@fz-juelich.de (U.S.)

7 Center of Plant Systems Biology and Biotechnology, 4000 Plovdiv, Bulgaria

8 Dipartimento di Scienze Agrarie, Alimentari e Ambientali, Università Politecnica delle Marche, 60131 Ancona, Italy

* Correspondence: r.papa@univpm.it; Tel.: +39-071-2204984/4280

\begin{abstract}
Mounting evidence indicates the key role of nitrogen $(\mathrm{N})$ on diverse processes in plant, including development and defense. Using a combined transcriptomics and metabolomics approach, we studied the response of seedlings to $\mathrm{N}$ starvation of two different tetraploid wheat genotypes from the two main domesticated subspecies: emmer and durum wheat. We found that durum wheat exhibits broader and stronger response in comparison to emmer as seen from the expression pattern of both genes and metabolites and gene enrichment analysis. They showed major differences in the responses to $\mathrm{N}$ starvation for transcription factor families, emmer showed differential reduction in the levels of primary metabolites while durum wheat exhibited increased levels of most of them to $\mathrm{N}$ starvation. The correlation-based networks, including the differentially expressed genes and metabolites, revealed tighter regulation of metabolism in durum wheat in comparison to emmer. We also found that glutamate and $\gamma$-aminobutyric acid (GABA) had highest values of centrality in the metabolic correlation network, suggesting their critical role in the genotype-specific response to $\mathrm{N}$ starvation of emmer and durum wheat, respectively. Moreover, this finding indicates that there might be contrasting strategies associated to GABA and glutamate signaling modulating shoot vs. root growth in the two different wheat subspecies.
\end{abstract}

Keywords: plant nutrition; Triticum turgidum; transcriptomics; metabolomics; stress; GABA; glutamate

\section{Introduction}

Availability and uptake of nitrogen $(\mathrm{N})$ is considered a major driver of growth [1]. Indeed, $\mathrm{N}$ is an essential nutrient for all organisms, including plants, and is required for the biosynthesis of macromolecules—such as proteins, nucleic acids, and chlorophyll—and for the synthesis of many secondary metabolites with different roles in adaptation and signaling [2]. As a result, $\mathrm{N}$ deficiency (limited availability) and starvation (complete absence) dramatically affects plant growth and metabolism [3]. 
However, only $30-50 \%$ of supplied $\mathrm{N}$ is taken up by crops [4], and the remainder is lost by denitrification or leaching into terrestrial ecosystems, causing eutrophication and contamination of drinking water [5]. Therefore, plant breeding efforts should be combined with improvement of crop management towards a more efficient use of $\mathrm{N}$ also to limit the use of fossil energy and environmental pollution [6,7]. Towards this key objective, it is necessary to understand how plants react and cope with low $\mathrm{N}$ availability and identify the molecular basis of the natural genetic variation for adaptation to low $\mathrm{N}$ conditions.

Tetraploid wheats (Triticum turgidum L. $2 \mathrm{n}=4 \mathrm{x}=28$; AABB genome), alongside with einkorn and barley, were domesticated in the Fertile Crescent, and durum wheat derived from domesticated emmer (Triticum turgidum ssp. dicoccum) through a rather long humandriven selection process, including distinct and sequential domestication bottlenecks and continuous gene flow from wild emmer (Triticum turgidum ssp. dicoccoides) [8-11].

Understanding the molecular mechanisms underlying the variation in traits responsible for the phenotypic plasticity in crop and wild species is a key step in addressing the challenges of modern agriculture, such as resilience to climate changes [12]. In particular, understanding the genetic variation in $\mathrm{N}$ metabolism in major crop species, such as wheat, is expected to provide novel strategies for crop improvement [13-15]. Moreover, tetraploid wheat appears a very interesting model to face this topic because the two main domesticated subspecies (emmer and durum wheat) were found to present a different phenotypic response to nitrogen availability [16].

In an increasing number of model and crop species, transcriptome studies have highlighted the complexity of the regulatory mechanisms involved in the control of leaf or root gene expression under both N-limiting and non-limiting conditions [17-20]. In addition, studies about the response of several cereal (e.g., rice, barley, sorghum, and wheat) to $\mathrm{N}$ starvation have highlighted differentially expressed genes (DEGs) involved in the response [20-24]. For instance, Chen et al. [25] and Hao et al. [26] compared gene expression changes in response to $\mathrm{N}$ stress in two maize and soybean genotypes with contrasting low $\mathrm{N}$ tolerance providing new insights useful to better understand the molecular mechanisms of nitrogen stress and improve the efficiency of nitrogen use for these crops. Furthermore, Gelli et al. [23] compared transcriptomic levels in four tolerant and three sensitive sorghum genotypes to low $\mathrm{N}$ condition showing as for the sensitive genotypes the $\mathrm{N}$ deficiency was accompanied by the increase of the DEGs associated with stress response (i.e., stimuli and oxidative stress) while the tolerant ones adapt to this condition producing major root mass to deal a more efficient uptake of nutrients.

Several works reported the combination of different 'omics' approaches (e.g., metabolomics and transcriptomics or proteomics) in the evaluation of different crops responses to $\mathrm{N}$ starvation [27-31]. Nevertheless, a limitation in these studies was that they were conducted using a single genotype. As an example, Vicente et al. [30] in their investigation used only one cultivar of durum wheat.

The analysis of gene expression can be complemented and expanded by using data on metabolite levels and their joint investigation with the help of network analysis approaches. The latter approaches have been useful in highlighting the role of metabolites in particular processes, but also for understanding the structure and regulation of the underlying metabolic and gene regulatory processes [32-36].

The aim of this study was to investigate and compare the transcriptomic and metabolomics responses of two genotypes of tetraploid wheats (one emmer landrace and one elite durum wheat cultivar-the parents of a RIL population developed at CREA-CI of Foggia (Italy) [37]) to $\mathrm{N}$ starvation at the vegetative stage (seedling growth) that showed phenotypic responses to differences in $\mathrm{N}$ availability. Our integrative analyses facilitated an in-depth molecular characterization and the comparison of tetraploid wheats responses to $\mathrm{N}$ starvation. 


\section{Results}

\subsection{Morphological and Physiological Differences under the Two N Conditions}

First, we investigated the effect of $\mathrm{N}$-starvation on plant growth by the evaluation of 13 complex traits, namely 12 morphological traits, including: total leaf number (TLN); total leaf area (TLA); shoot fresh weight (SFW); primary visible root length (PRL); lateral visible root length (LRL); total visible root length (TRL); visible root system depth (RSD); visible root system width (RSW); root dry weight (RDW); specific root length (SRL); total visible root length/total leaf area ratio (TRL/TLA); lateral visible root length/primary visible root length ratio (LRL/PRL), as well as one physiological trait, leaf chlorophyll content (SPAD) in emmer (Molise Sel. Colli) and durum wheat (Simeto). Table 1 shows the significant changes according to a two-way ANOVA due to genotype $(\mathrm{G}), \mathrm{N}$ treatment $(\mathrm{N})$, and their interaction $(\mathrm{GxN})$. The traits TLA and SFW showed significant differences due to G (higher values in durum wheat) and $\mathrm{N}$ effect (higher values under optimal $\mathrm{N}$ condition). There were three measured traits, namely TLN, RDW, and TRL/TLA which were significantly affected by $\mathrm{N}$ starvation. TLN was higher at $+\mathrm{N}$ in comparison to $-\mathrm{N}$ (5.19 and 3.50, respectively), RDW was higher at $-\mathrm{N}$ respect to $+\mathrm{N}(0.03$ and 0.02 , respectively) and the ratio TRL/TLA was three-fold greater in starvation than optimal $\mathrm{N}$ condition. Finally, for SRL and SPAD, a significant effect due to the GxN interaction was observed. For instance, emmer at optimal $\mathrm{N}$ exhibited the largest value of SRL in comparison to emmer at $\mathrm{N}$ starvation and durum wheat in both $\mathrm{N}$ conditions (about 2-fold greater than the mean of the other values). The opposite held for SPAD, for which durum wheat showed the highest value at optimal $\mathrm{N}$ compared to durum wheat at $-\mathrm{N}$ and for both treatments of emmer (about 1.5 fold greater than the mean of the other values).

Table 1. Summary statistics (ANOVA) and differential behavior for 12 morphological and one physiological trait in emmer and durum wheat under two $\mathrm{N}$ conditions: $\mathrm{N}$ starvation $(-\mathrm{N})$ and optimal $\mathrm{N}(+\mathrm{N})$ condition. Data are reported as mean \pm SE.

\begin{tabular}{|c|c|c|c|}
\hline \multicolumn{4}{|c|}{ Genotype Effect (G) } \\
\hline & Emmer & Durum Wheat & $p$ Value \\
\hline TLN & $3.88 \pm 0.54$ & $4.81 \pm 0.48$ & n.s. \\
\hline $\operatorname{TLA}\left(\mathrm{cm}^{2}\right)$ & $24.85 \pm 5.66 b$ & $41.92 \pm 8.39 \mathrm{a}$ & 0.0304 \\
\hline SFW (g) & $0.63 \pm 0.19 b$ & $1.17 \pm 0.30 \mathrm{a}$ & 0.0453 \\
\hline PRL (cm) & $155.58 \pm 26.79$ & $172.72 \pm 25.42$ & n.s. \\
\hline LRL $(\mathrm{cm})$ & $20.49 \pm 7.00$ & $10.89 \pm 4.04$ & n.s. \\
\hline TRL (cm) & $176.07 \pm 32.17$ & $183.62 \pm 27.96$ & n.s. \\
\hline RSD (cm) & $62.84 \pm 5.38$ & $65.34 \pm 3.66$ & n.s. \\
\hline RSW (cm) & $23.31 \pm 3.26$ & $22.82 \pm 3.22$ & n.s. \\
\hline RDW (g) & $0.02 \pm 0.01$ & $0.03 \pm 0.00$ & n.s. \\
\hline SRL $\left(\mathrm{m} \mathrm{g}^{-1}\right)$ & $107.31 \pm 15.77$ a & $67.69 \pm 5.99 b$ & 0.0094 \\
\hline TRL/TLA $\left(\mathrm{cm} \mathrm{cm}^{-2}\right)$ & $7.92 \pm 1.65$ & $5.98 \pm 1.62$ & n.s. \\
\hline LRL/PRL & $0.11 \pm 0.04$ & $0.06 \pm 0.02$ & n.s. \\
\hline SPAD & $26.55 \pm 1.22 b$ & $34.91 \pm 2.24 \mathrm{a}$ & $<0.0001$ \\
\hline \multicolumn{4}{|c|}{ Nitrogen Effect (N) } \\
\hline & $-\mathbf{N}$ & $+\mathrm{N}$ & $p$ Value \\
\hline TLN & $3.50 \pm 0.19 b$ & $5.19 \pm 0.59 \mathrm{a}$ & 0.0173 \\
\hline $\operatorname{TLA}\left(\mathrm{cm}^{2}\right)$ & $19.98 \pm 1.43 b$ & $46.79 \pm 8.35 \mathrm{a}$ & 0.0023 \\
\hline SFW (g) & $0.42 \pm 0.05 b$ & $1.39 \pm 0.28 \mathrm{a}$ & 0.0017 \\
\hline PRL (cm) & $191.72 \pm 21.60$ & $136.59 \pm 26.47$ & n.s. \\
\hline LRL (cm) & $15.28 \pm 5.19$ & $16.10 \pm 6.70$ & n.s. \\
\hline TRL $(\mathrm{cm})$ & $206.99 \pm 24.99$ & $152.69 \pm 31.39$ & n.s. \\
\hline RSD (cm) & $70.28 \pm 2.54$ & $57.90 \pm 5.04$ & n.s. \\
\hline RSW (cm) & $24.79 \pm 3.08$ & $21.34 \pm 3.27$ & n.s. \\
\hline RDW (g) & $0.03 \pm 0.00 a$ & $0.02 \pm 0.00 \mathrm{~b}$ & 0.0228 \\
\hline $\operatorname{SRL}\left(\mathrm{m} \mathrm{g}^{-1}\right)$ & $70.31 \pm 5.93 b$ & $104.69 \pm 16.65 \mathrm{a}$ & 0.0201 \\
\hline TRL/TLA $\left(\mathrm{cm} \mathrm{cm}^{-2}\right)$ & $10.57 \pm 1.28 \mathrm{a}$ & $3.34 \pm 0.45 b$ & 0.0002 \\
\hline LRL/PRL & $0.07 \pm 0.02$ & $0.10 \pm 0.04$ & n.s. \\
\hline SPAD & $26.91 \pm 1.24 b$ & $34.55 \pm 2.41 \mathrm{a}$ & 0.0001 \\
\hline
\end{tabular}


Table 1. Cont.

\begin{tabular}{|c|c|c|c|c|c|}
\hline \multicolumn{6}{|c|}{ Genotype $\times$ Nitrogen Interaction Effect $(G \times N)$} \\
\hline & Emmer $\times(-N)$ & Emmer $\times(+N)$ & $\underset{(-N)}{\operatorname{Durum} \text { Wheat } \times}$ & $\underset{(+N)}{\text { Durum Wheat } \times}$ & $p$ Value \\
\hline TLN & $3.00 \pm 0.00$ & $4.75 \pm 0.92$ & $4.00 \pm 0.00$ & $5.63 \pm 0.80$ & n.s. \\
\hline TLA $\left(\mathrm{cm}^{2}\right)$ & $17.22 \pm 1.21$ & $32.48 \pm 10.45$ & $22.74 \pm 1.75$ & $61.10 \pm 8.94$ & n.s. \\
\hline SFW $(g)$ & $0.34 \pm 0.04$ & $0.93 \pm 0.32$ & $0.50 \pm 0.07$ & $1.85 \pm 0.35$ & n.s. \\
\hline PRL (cm) & $189.27 \pm 31.72$ & $121.89 \pm 39.82$ & $194.16 \pm 34.17$ & $151.28 \pm 39.25$ & n.s. \\
\hline LRL (cm) & $18.60 \pm 8.34$ & $22.38 \pm 12.53$ & $11.96 \pm 6.99$ & $9.83 \pm 5.13$ & n.s. \\
\hline TRL $(\mathrm{cm})$ & $207.87 \pm 39.64$ & $144.27 \pm 50.83$ & $206.12 \pm 36.65$ & $161.11 \pm 44.36$ & n.s. \\
\hline RSD (cm) & $68.69 \pm 4.09$ & $56.98 \pm 9.76$ & $71.86 \pm 3.41$ & $58.82 \pm 4.74$ & n.s. \\
\hline RSW (cm) & $28.72 \pm 3.47$ & $17.89 \pm 4.25$ & $20.87 \pm 4.68$ & $24.78 \pm 4.89$ & n.s. \\
\hline RDW (g) & $0.03 \pm 0.01$ & $0.01 \pm 0.00$ & $0.03 \pm 0.01$ & $0.02 \pm 0.00$ & n.s. \\
\hline SRL $\left(\mathrm{m} \mathrm{g}^{-1}\right)$ & $75.75 \pm 7.06 b$ & $138.87 \pm 21.15$ a & $64.87 \pm 9.72 b$ & $70.52 \pm 8.21 b$ & 0.0449 \\
\hline TRL/TLA $\left(\mathrm{cm} \mathrm{cm}^{-2}\right)$ & $11.68 \pm 1.71$ & $4.17 \pm 0.54$ & $9.46 \pm 1.98$ & $2.50 \pm 0.43$ & n.s. \\
\hline LRL/PRL & $0.09 \pm 0.04$ & $0.14 \pm 0.07$ & $0.06 \pm 0.03$ & $0.05 \pm 0.02$ & n.s. \\
\hline SPAD & $24.35 \pm 0.91 b$ & $28.75 \pm 1.72 b$ & $29.48 \pm 1.40 \mathrm{~b}$ & $40.35 \pm 1.31 \mathrm{a}$ & 0.0353 \\
\hline
\end{tabular}

TLN: Total leaf number; TLA: Total leaf area $\left(\mathrm{cm}^{2}\right)$ Calculated on all the leaf as leaf length. maximum width.0.858 (Kalra and Dhiman. 1976); SFW: Shoot fresh weight (g); PRL: Primary visible root length (cm); LRL: Lateral visible root length (cm); TRL: Total visible root length (cm); RSD: Visible root system depth (cm); RSW: Visible root system width (cm); RDW: Root dry weight $(\mathrm{g})$; TRL/TLA: Total visible root length/total leaf area $\left(\mathrm{cm} \mathrm{cm}^{-2}\right)$; SRL: specific root length (defined as TRL/RDW); SPAD: Leaf chlorophyll content (SPAD units). Values annotated in bold are significantly different (Student's/Tukey's test) and the character "a"/"b" implies the higher/lower observed value for each significant change between the genotypes ( $G$ effect), the two $N$ conditions ( $N$ Effect) and their interaction $(G \times N$ effect); n.s.: not significant.

\subsection{Transcriptomic Differences between the Two N Conditions}

A global transcriptome analysis for the comparison of the two analyzed tetraploid wheat genotypes was performed on the leaves tissue using RNA-Seq Illumina technology resulting in 9.9 to 19.5 million reads per genotype (Table S1). These numbers were reduced after additional processing steps (see Methods) by $4.3-7.5 \%$, depending on the sample. The cleaned reads were mapped on the bread wheat reference covering, on average, $70 \%$ of all reads in the analyzed genotypes (Table S1).

We used the mapped reads to assess the DEGs in each genotype between the two $\mathrm{N}$ conditions, i.e., $\mathrm{N}$ starvation and optimal $\mathrm{N}$ condition. The total number of genes expressed in emmer and durum wheat were 27,792 and 28,812 , respectively. The number of significant DEGs for emmer was 1788, while in durum wheat it was 3129. The number of DEGs specific to durum wheat was approximately 3.2-fold larger than in emmer, and the number of DEGs common to the two genotypes was 1094 (Figure 1A). In addition, the number of the upregulated DEGs in N starvation compared to optimal N condition, specific to durum wheat was 2.5-fold larger than those specific to emmer, while the number of downregulated DEGs specific to durum wheat was 3.5-fold larger than those specific to emmer (Figure 1B). Therefore, we found a stronger transcriptional response in durum wheat to the change in $\mathrm{N}$ availability in comparison to emmer.

\subsection{Functions of DEGs in Emmer and Durum Wheat between the Two N Conditions}

The functional annotation of DEGs either common or specific to one of the genotypes, were reported in Table S2. Several DEGs were directly involved in N metabolism and transport. The key DEGs involved in nitrate assimilation, i.e., the gene coding for asparagine synthetase and aspartate aminotransferase, were upregulated in both genotypes. In durum wheat, the gene coding for nitrate reductase was upregulated, while the genes orthologous to Arabidopsis glutamine synthetase and glutamate dehydrogenase family were downregulated in response to $\mathrm{N}$-starvation (Table S2). A similar result was reported for the response of durum wheat leaves to $\mathrm{N}$ chronic starvation during grain filling [15]. One nitrate transporter and two ammonium transporters were found among the DEGs in emmer (Table S2). Interestingly, other DEGs associated with the translocation of other nutrient (potassium (8 genes), phosphate (1- [PhO1] gene), sulfate (1 gene), zinc (1 gene), 
calcium (8 genes), copper (2 genes), magnesium (3 genes), and ABC transporter (6 genes)) also changed under $\mathrm{N}$ starvation (Table S2).

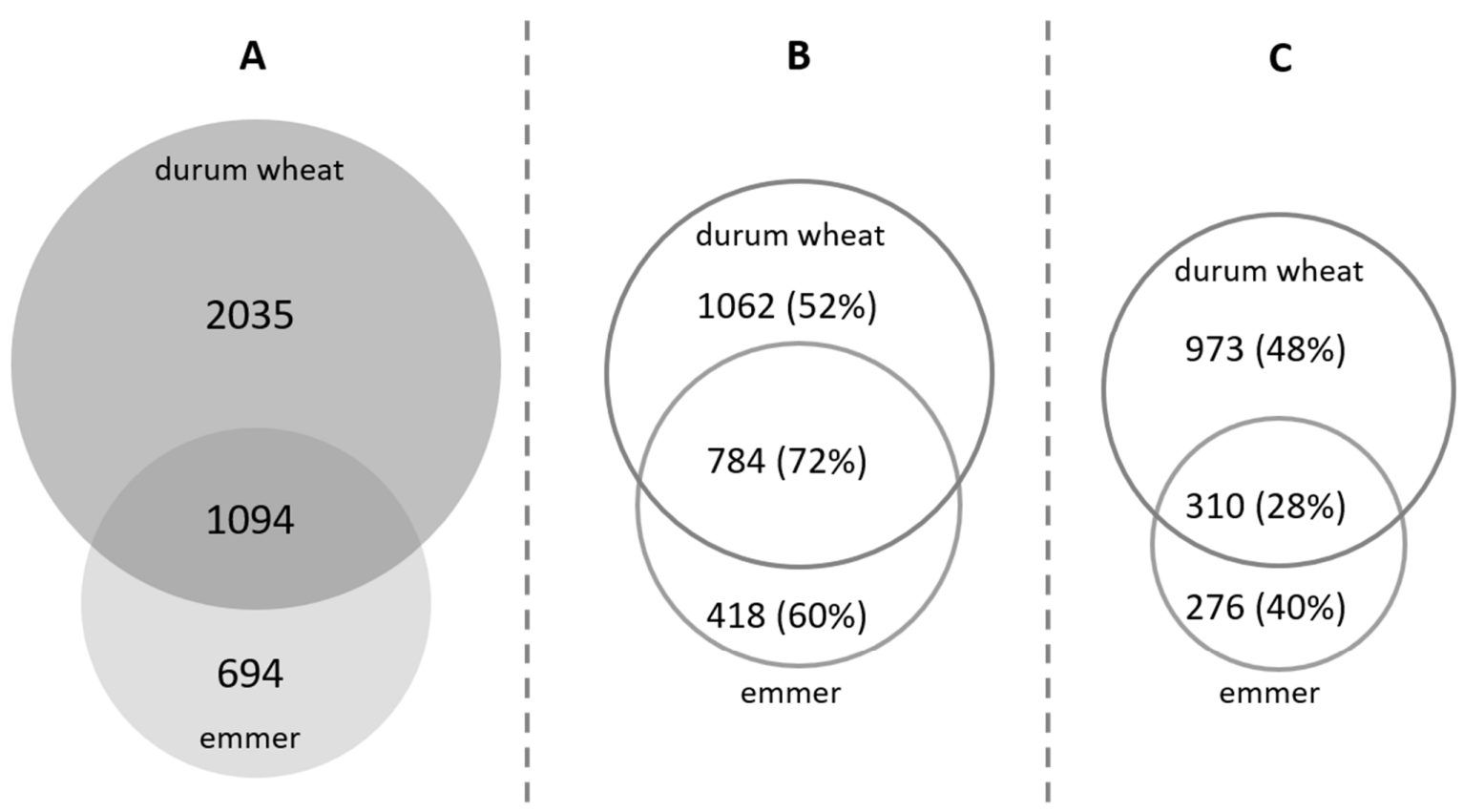

A: total DEGs between $-\mathrm{N}$ and $+\mathrm{N}$ for durum wheat and emmer; $\mathrm{B}$ : DEGs up-regulated between $-\mathrm{N}$ and $+\mathrm{N}$

for durum wheat and emmer; C: DEGs down-regulated between $-\mathrm{N}$ and $+\mathrm{N}$ for durum wheat and emmer

Figure 1. Differentially expressed genes between $\mathrm{N}$ starvation $(-\mathrm{N})$ and optimal $\mathrm{N}(+\mathrm{N})$ conditions in durum wheat and emmer. (A) Total number of DEGs between $-\mathrm{N}$ and $+\mathrm{N}$ for durum wheat and emmer; (B) number (and relative percentage of the total) of DEGs upregulated between $-\mathrm{N}$ and $+\mathrm{N}$ for durum wheat and emmer; (C) number (and relative percentage of the total) of DEGs downregulated between $-\mathrm{N}$ and $+\mathrm{N}$ for durum wheat and emmer.

A general alteration was observed for genes participating in carbon metabolism, especially for those involved in glycolysis, tricarboxylic acid cycle (TCA), photosynthesis and photorespiration, particularly in durum wheat (Table S2). Notably, gene coding for phosphoglycerate kinase (PGK), pyruvate kinase (PK), glyceraldehyde 3-phosphate dehydrogenase (GAPDH), and fructose bisphosphate aldolase were upregulated and specific to durum wheat, while pyruvate dehydrogenase E1-component subunit alpha (PDHA), pyrophosphate-fructose 6-phosphate 1-phosphotransferase subunit alpha (PFP-ALPHA), and ATP-dependent 6-phosphofructokinase (PFK1) were upregulated and specific to emmer. Concerning the pentose phosphate pathway, one DEG encoding for glucose-6phosphate dehydrogenase (G6PD) was upregulated in both genotypes, while two orthologs to ribose-5-phosphate-isomerase (Rpi) were upregulated only in durum wheat. Notably, orthologues to RuBisCO (5 DEGs) and ferrodoxin (3 DEGs) were upregulated only in durum wheat.

Transcription factors from the ARFs (5 DEGs) and NF-Y (3 DEGs) families were found to be downregulated in both genotypes, while the MYB family (1 DEGs) was upregulated in durum wheat and PTACs (5 DEGs) families were upregulated in both genotypes (Table S2). In addition, 35 protein kinases (PKs) were identified as DEGs, of which 13 were common to the two genotypes, while 6 and 16 were found as DEGs specific to emmer and durum wheat, respectively. Generally, N starvation causes several stress responses. About two thirds of DEGs common or specific to each genotype were upregulated, and among them there were several antioxidant enzymes encoding genes, such as: superoxide dismutase (SOD), catalase (CAT), glutathione peroxidase (GPX), peroxiredoxin (Prx), and lipoxyge- 
nases (LOXs), as well as enzymes of the ascorbate-glutathione cycle, such as: glutathione reductase (GR) or those involved in the biosynthesis of secondary metabolites (Table S2).

\subsection{GO Enrichment Analysis of DEGs}

To investigate the transcriptomic changes in leaves of emmer and durum wheat under the two N conditions, we assessed the GO enrichment in the set of DEGs (see Methods).

The GO terms identified were categorized into 21 and 23 categories for emmer and durum wheat, respectively (Figure 2, Table S3). In both genotypes, the highest number of DEGs upregulated were included in the categories 'cellular process', 'metabolic process', 'binding', and 'catalytic' while those that were differentially downregulated were principally grouped into 'binding' and 'catalytic' categories. Differences between the two genotypes were observed with respect to the molecular function category 'transcription regulator' which was enriched in both the down- and upregulated DEGs in emmer and durum wheat, respectively, and in the GO terms associated with biological process categories 'regulation of biological process' and 'reproductive process', which were only enriched in durum wheat for upregulated DEGs.

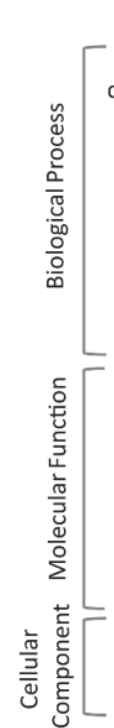

emmer

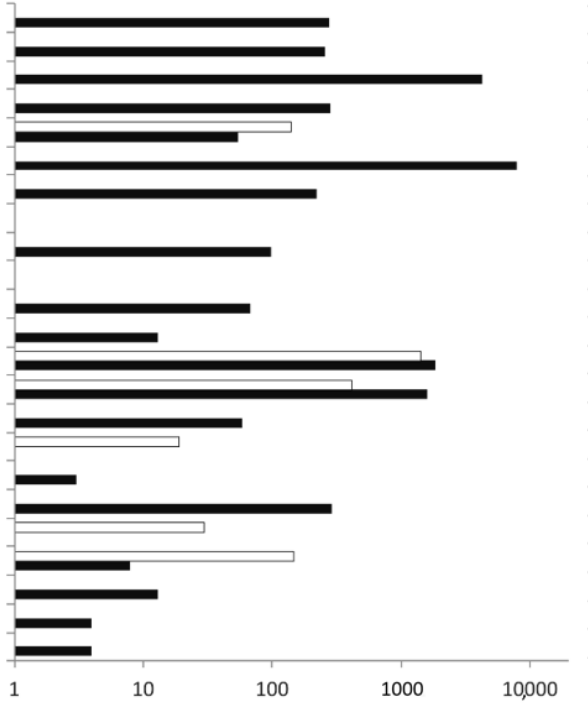

durum wheat

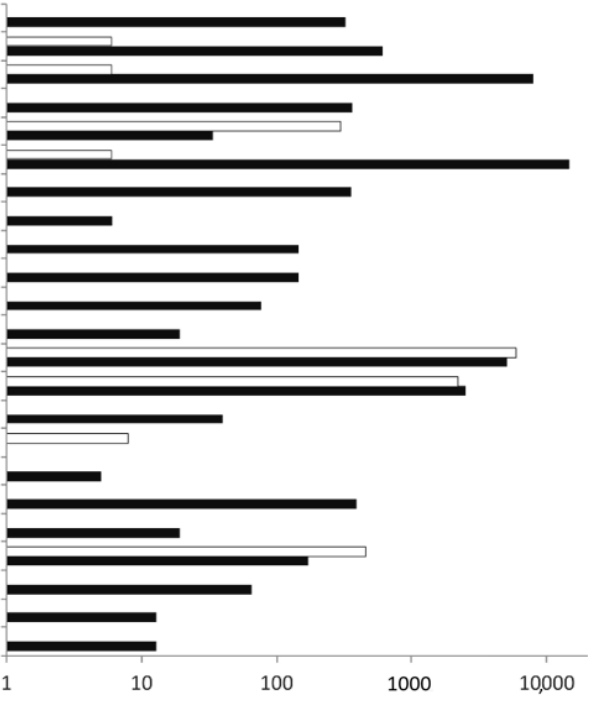

$\square$ DEGs down-regulated $\quad$ DEGs up-regulated

Figure 2. Comparison of Gene Ontology classifications of DEGs in emmer and durum wheat. Black and white bars indicate the number of up- and downregulated DEGs, respectively. All DEGs are categorized into 21 and 23 functional groups based on GO classification for emmer and durum wheat, respectively.

Extended list of over represented GO terms with the $p$-value of at most $10^{-5}$ for emmer and durum wheat is reported in Table S4. Notably, all GO terms of the categories "cellular process", "metabolic process", "binding", and "catalytic" (e.g., those involving the nitrogen) which were enriched in emmer were also found in durum wheat. Durum wheat showed also specific over-represented GO terms in several categories; for instance, these included the cellular amino acid, oxoacid or organic acid metabolic processes, or the metabolic/biosynthetic process of isopentenyl diphosphate (Table S4). In addition, regarding the categories "binding" and "catalytic activity", durum wheat showed different over-represented GO terms among the DEGs differentially up- and downregulated. For example, GO terms of oxidoreductase, ligase, hydrolase (on glycosyl bond or O-glycosyl compounds), lyase and transferase activity were not enriched in the downregulated DEGs, while GO terms of kinase, protein kinase, protein serine/threonine kinase and phosphotransferase activity were not enriched on the upregulated DEGs (Table S4). 


\subsection{Metabolic Differences between the Two N Conditions}

A total of 46 metabolites were identified and quantified using GC-MS (see Methods). These included 41 polar and 5 non-polar compounds, divided into the following compound classes: amino acids, organic acids, sugars and sugar alcohols, fatty acids, polycosanol, and phytosterols. The data were analyzed using two-way ANOVA and significant differences $(p \leq 0.05)$ for 23 metabolites including the TCA cycle intermediates, some sugars, shikimic, and quinic acids, several amino acids and GABA were reported (Table S5). For all of the 23 metabolites, with the exception of tryptophan that showed only the genotype effect $(G)$, a strong significant effect due to the interaction of the genotype and $N$ treatment $(G \times N)$ was observed. Apart the $\mathrm{G} \times \mathrm{N}$ effect, for aconitic and shikimic acids significant differences were observed due to $G$ effect while five metabolites (glutamic acid, aspartic acid, citric acid, saccharic acid, and maltitol) showed also significant differences due to both $\mathrm{G}$ and $\mathrm{t}$ $\mathrm{N}$ effects. A higher content of metabolites was found in emmer under optimal $\mathrm{N}$ condition in comparison to durum wheat (see Figure 3 for illustrative comparison).

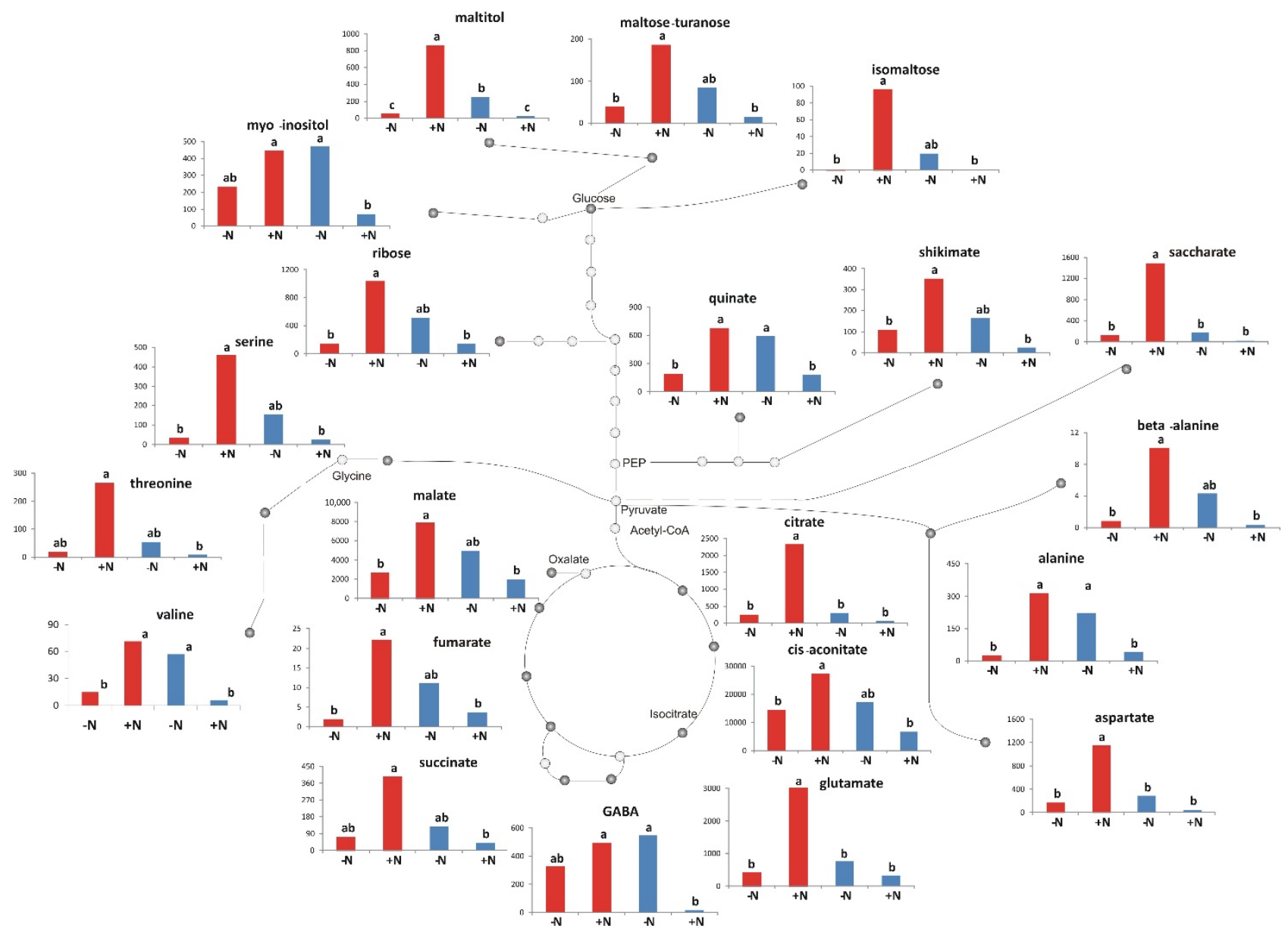

Figure 3. Metabolites exhibiting significant variation for emmer (red bars) and durum wheat (blue bars) under starvation $(-\mathrm{N})$ and optimal $(+\mathrm{N})$ levels due to the effect of $\mathrm{G} \times \mathrm{N}$ interaction. Bars with different letters are significantly different $(p<0.05$, Tukey's test) and the character " $\mathrm{a}$ " $/$ " $\mathrm{b}$ " and "ab" implies the higher/lower and intermediate observed value for each significant change.

\subsection{Network Analysis of Combined Data Sets}

In general, the correlation structure among the combined data sets (transcripts and metabolites) of each genotype can be represented by a network, where a node denotes a transcript, or a metabolite and an edge stand for the presence of significant Pearson correlation between the data associated to the nodes. Overall, durum wheat showed 2.8-fold more 
significant correlations in comparison to emmer (Table 2). The intersection of the networks from the two genotypes included $\sim 397,000$ edges, of which $99.3 \%$ did not demonstrate significant differences between the two networks (using Fisher's z-transformation, see Methods). The latter set of edges (with no significant differences between the networks obtained for each genotype; by applying Fisher's $z$ transformation) is said to comprise the common network between the two genotypes that represents the $31.5 \%$ and $11.2 \%$ of the total correlations in the networks of emmer and durum wheat, respectively.

Table 2. Networks of emmer, durum wheat, intersection, and common networks of transcripts and metabolites data.

\begin{tabular}{|c|c|c|c|c|c|}
\hline & Emmer & Durum Wheat & $\begin{array}{c}\text { (Durum } \\
\text { Wheat/Emmer) }\end{array}$ & Intersection & $\begin{array}{c}\text { Common } \\
\text { (Accepting the } \\
\text { Fisher Ztest NULL } \\
\text { Hypothesis) }\end{array}$ \\
\hline Number of edges in total & $1,249,637$ & $3,500,971$ & 2.8 & 396,571 & 393,779 \\
\hline $\begin{array}{c}\text { Number of edges } \\
\text { DEG-DEG }\end{array}$ & $1,237,748$ & $3,473,768$ & 2.8 & 394,015 & 393,719 \\
\hline $\begin{array}{l}\text { Number of edges } \\
\text { metabolite-metabolite }\end{array}$ & 185 & 157 & 0.85 & 65 & 60 \\
\hline $\begin{array}{l}\text { Number of edges } \\
\text { DEG-metabolites }\end{array}$ & 11,704 & 27,046 & 2.3 & 2491 & 0 \\
\hline Number of nodes & 1829 & 3167 & 1.7 & 1129 & 1127 \\
\hline Number of central nodes & 260 & 479 & 1.8 & 367 & 398 \\
\hline $\begin{array}{l}\text { Number of edges to the } \\
\text { central nodes: } \\
\text { DEGs-significantly } \\
\text { behaved metabolites * }\end{array}$ & 1898 & 4590 & 2.4 & 1217 & 0 \\
\hline
\end{tabular}

* Significantly behaved metabolites considering the effect of $\mathrm{G}, \mathrm{N}$, and $\mathrm{G} \times \mathrm{N}$ of the ANOVA model.

Because we are interested in understanding if the differences in correlation could reflect the differences in regulation of transcripts and metabolites, we considered only the significant correlations between DEGs and significantly altered metabolites under the two $\mathrm{N}$ conditions; the number of such correlations in durum wheat was 2.3-fold larger than in emmer. Focusing the attention only on those metabolites that showed differential behavior between the two $\mathrm{N}$ conditions, as reported above, we observed that for emmer GABA is involved in the smallest number of edges (12), while maltitol participates in the largest number of edges (1667). In durum wheat, we find an almost contrasting situation, isomaltose was involved in the smallest number of edges (28), while GABA exhibited the largest number of edges (2954) (Table S6).

The effect of the observed differences between the correlation structures (i.e., networks) obtained for both genotypes can be investigated for each node and can be summarized by its centrality in the network. In this context, we selected those nodes showing the centrality measures (i.e., degree and betweenness) greater than the corresponding mean values in each genotypic-specific network. Considering the nodes of the two genotype-specific networks, those with a central role included 260 and 479 genes in emmer and durum wheat, respectively (Table 2). In durum wheat also the metabolites: myo-inositol, quinic acid and valine showed high values for both centrality measures. To refine the network, we next included only DEGs with high values of centrality and only metabolites that were significantly contrasted between the two $\mathrm{N}$ conditions. In general, the total number of edges decreased of about $79 \%$ and $85 \%$ for emmer and durum wheat, respectively (Table S6). The total number of edges between central DEGs and differentially behaved metabolites in durum wheat is higher than those in emmer by 3.6-fold for alanine and 479-fold for GABA. In contrast, in emmer, the number of edges between central DEGs and significantly contrasted metabolites-glutamic acid, isocitric acid, isomaltose, saccharic acid, serine, succinic acid, and threonine-were higher than those in durum wheat. Noteworthy, with 
aspartic acid, citric acid, fumaric acid and maltitol the number of edges was the same in both genotype-specific networks.

\subsection{Function of DEGs Having a Central Role in the Networks}

To evaluate the common or specific responses to $\mathrm{N}$ starvation in the two genotypes, we looked for the annotated functions of the DEGs shared between the two genotypespecific networks with a central role in at least one of the two networks (Table S7). Several DEGs related to photosynthesis were expressed in both genotypes but in some cases, they showed a central role only in emmer-specific network (e.g., chlorophyll synthase (CHLG)) while, in contrast carboxyl-terminal-processing peptidase 3 (CTPA3), cytochrome $\mathrm{c}$ biogenesis protein (CCS1), and magnesium-chelatase subunit ChlD (ChlD) were found to have a central role in the durum wheat-specific network. In the network specific to emmer the most central nodes coded for pyruvate phosphate dikinase 1 (PPDK) and pyruvate dehydrogenase E1component subunit alpha-3 (PDH-E1 ALPHA) which were down- and upregulated, respectively.

In durum wheat-specific network, DEGs related to proteolysis as well as the synthesis of the cofactor FMN, that were upregulated, had a central role in the network, and at the same time, Allantoinase (ALN), a key enzyme for biogenesis and degradation of allantoin and its degradation derivatives, essential in the assimilation, metabolism, transport, and storage of nitrogen in plants, was among the central nodes.

In both genotype-specific networks, different DEGs involved in the chloroplast development showed central roles (Table S7). Among the central DEGs, there were several genes related to detoxification and plant stress responses caused by $\mathrm{N}$ starvation. Only one DEG (Traes_2BL_CCD296233, downregulated) encoding for the Stress Enhanced Protein 2 (SEP2), showed a central role in both genotype-specific networks (Table S7).

To highlight the differences between emmer and durum wheat, we also considered the putative annotation of the central DEGs in each genotype-specific network (see Table S8). In emmer, several genes involved in $C$ metabolism or related to stress conditions responses were upregulated; at the same time, a DEG related to carbonic anhydrase (EC 4.2.1.1), involved in $\mathrm{N}$ metabolism, was downregulated. In contrast, in durum wheat, several DEGs related to photosynthesis were differently regulated, i.e., chlorophyll synthase and the ferritin were upregulated while the ferrochelatase was downregulated. Importantly in durum wheat-specific network, there is also a central DEG (Traes_3AS_3CB8A9C01) for glutamate decarboxylase (GAD) which was upregulated.

Figure 4 represented the genotype-specific networks of DEGs-metabolites reported in Tables S7 and S8 for emmer (A) and durum wheat (B), respectively. As illustrated, the network structure was different between the two genotypes; consistently emmer-specific network showed a higher number of negative correlations between DEGs and metabolites while durum wheat-specific network has higher number of positively correlated DEGs and metabolites pairs. Of note, glutamic acid and valine were the metabolites highly connected to the other nodes in emmer-specific network while GABA, quinic acid, myo-inositol and valine were highly connected to the rest of the nodes in durum wheat-specific network. 
A

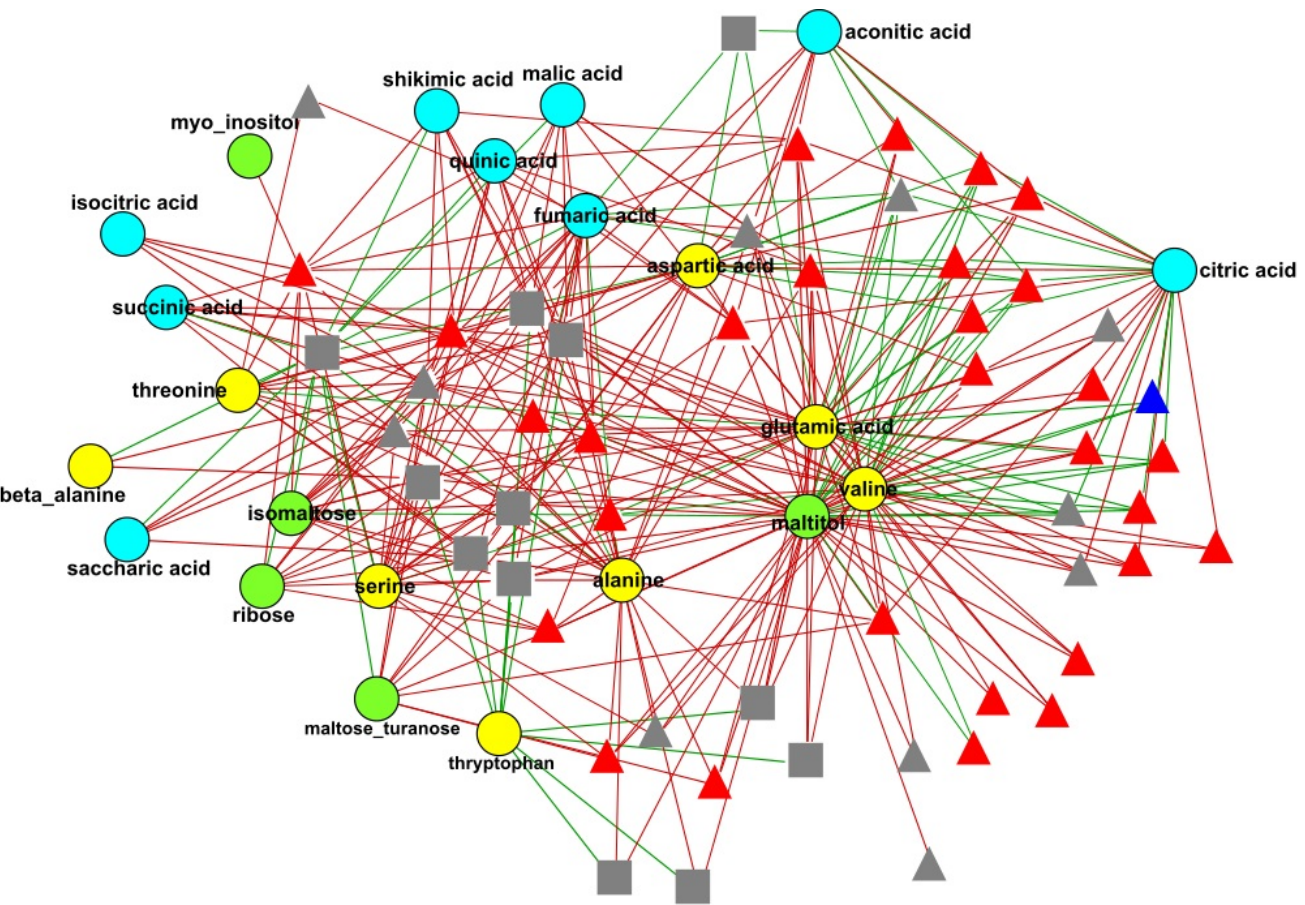

B

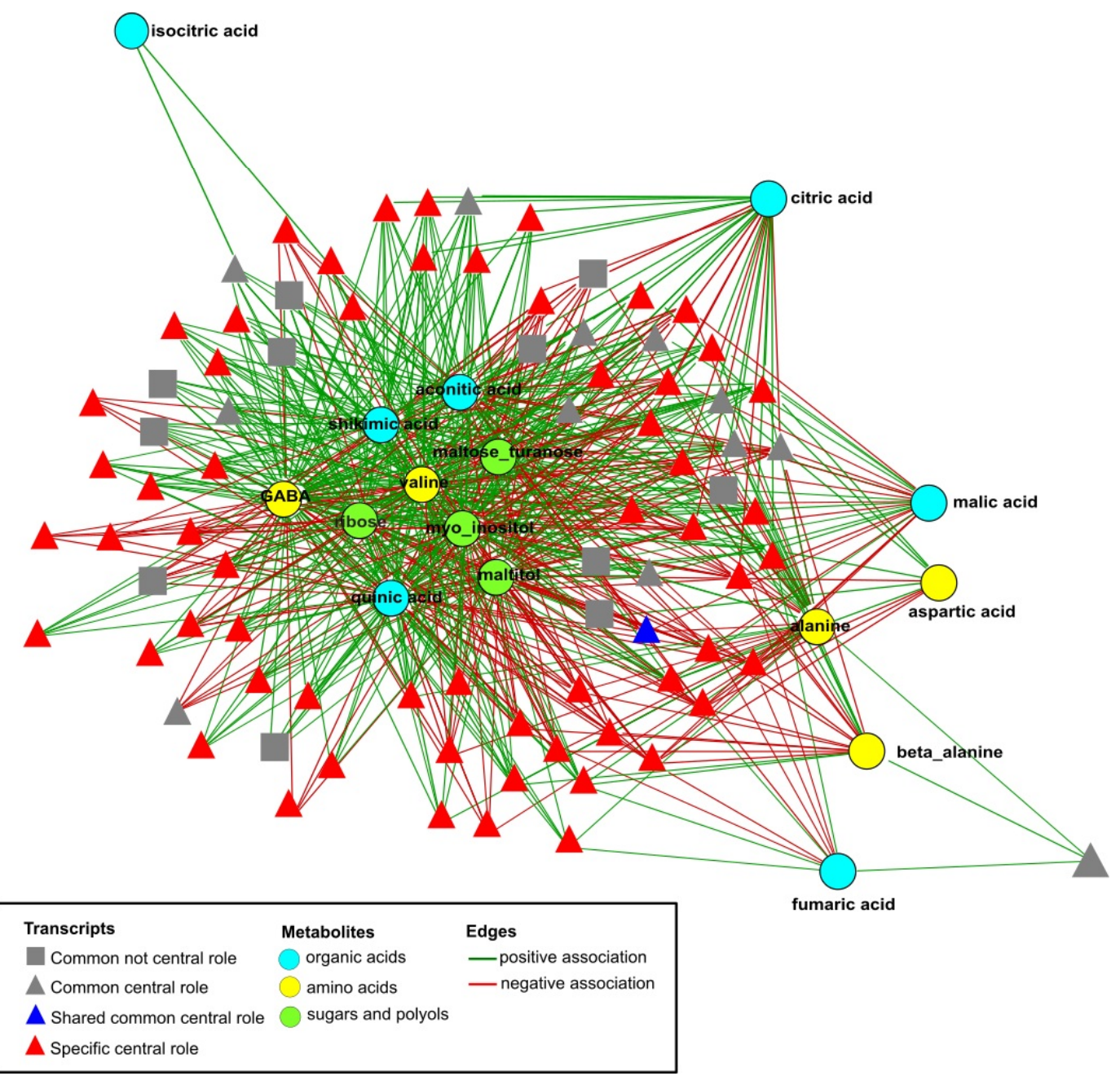

Figure 4. Genotype-specific DEGs-metabolites correlation networks, emmer (A) and durum wheat (B). 


\subsection{DEGs Position on the Genome}

We have also considered the position of DEGs in both genotypes on the physical map. In general, for each chromosome durum wheat showed a higher number of DEGs compared to emmer. In both genotypes, the larger number of DEGs was located on chromosome $2 \mathrm{~A}$, $2 \mathrm{~B}, 4 \mathrm{~A}, 5 \mathrm{~A}$, and $5 \mathrm{~B}$, while lower number of genes was found in the chromosome $3 \mathrm{~B}$. Few genes were in chromosome 6B in emmer (Figure S1).

Figure 5 illustrates the location of down- and upregulated DEGs with central role in the corresponding genotype-specific networks. Observing the results, the higher number of central nodes in the emmer-specific network was located on chromosome $2 \mathrm{~B}, 4 \mathrm{~B}$, and $5 \mathrm{~A}$, while for durum wheat-specific network the higher number of central DEGs was located on chromosome 2A, 2B, $4 \mathrm{~A}$, and $5 \mathrm{~B}$.
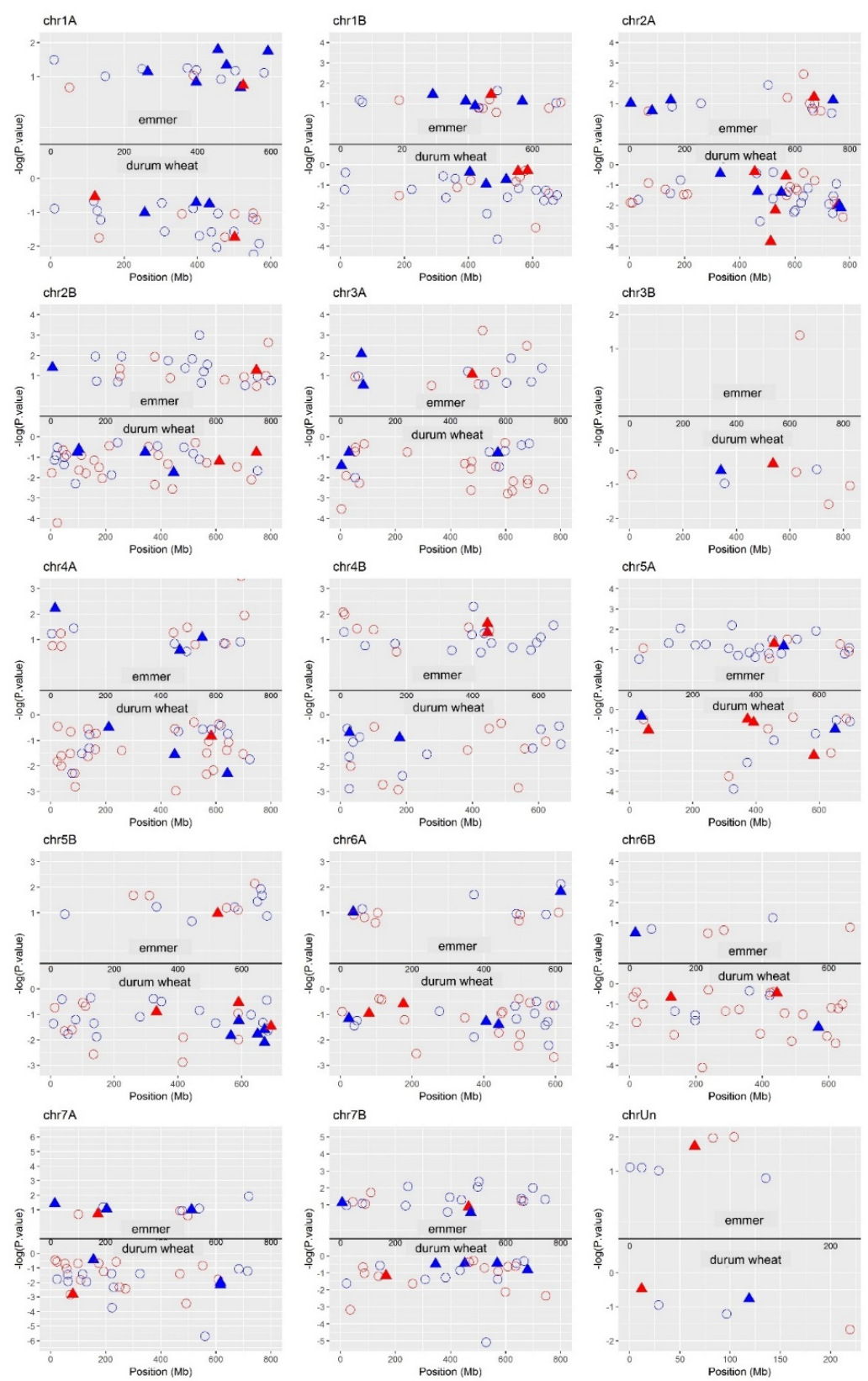

Figure 5. Position of the central DEGs (circles) in emmer- and durum wheat-specific networks on the physical map. DEGs having putative annotations were shown with filled triangles. In red and blue the DEGs down- and upregulated, respectively. 


\subsection{Environmental Effect}

In order to consider the environmental effect on the transcriptome analysis, we also considered and compared the DEGs in durum wheat vs. emmer in nitrogen starvation $(-\mathrm{N})$ and durum wheat vs. emmer in optimal nitrogen $(+\mathrm{N})$ conditions. The number of genes differentially expressed were 1890 and 1740 at $-\mathrm{N}$ and $+\mathrm{N}$, respectively. Under the $-\mathrm{N}$ condition the number of DEGs up- and downregulated was comparable (980 and 910, respectively), while under $+\mathrm{N}$ condition they were 1077 and 663, respectively. Figure S2A reports the Venn diagram of the DEGs shared between emmer and durum wheat (for the total number see Figure 1) and expressed also in the two $\mathrm{N}$ conditions considered. Only 42 DEGs, representing the $3.8 \%$ of those in common between the two genotypes, were expressed in all the comparisons, 81 ( $7.4 \%$ of total in common) and 23 ( $2 \%$ of total in common) were differentially expressed under $-\mathrm{N}$ and $+\mathrm{N}$, respectively. Considering the specific genes of durum wheat (Figure S2B), 71 DEGs (3.5\% of total durum specific) were found as DEGs under $-\mathrm{N}, 122$ (6\% of total durum specific) under $+\mathrm{N}$ and 91 (4.5\% of total durum specific) in both $\mathrm{N}$ conditions. In the case of emmer (Figure S2C), 118 specific DEGs were shared with $-\mathrm{N}$ (representing the $16.8 \%$ of total emmer specific), 27 DEGs were shared with $+\mathrm{N}$ ( $3.9 \%$ of total emmer specific) and only 16 DEGs (2.3\% of total emmer specific) in both conditions.

Finally, we evaluated if the DEGs, having a central role in the two genotype-specific networks previously described, were affected also by the environment. In general, few central genes were affected by the environment: four DEGs among those in common to both genotypes, seven and six DEGs among those specific of durum wheat and emmer, respectively. Considering those DEGs in common, only one gene (Traes_2BL_CCD296233), having a central role in the corresponding two networks, was differentially expressed also at $-\mathrm{N}$ and $+\mathrm{N}$; another common gene was also found as a DEG under both $\mathrm{N}$ condition but it has a central role only in the emmer network. The other two common genes were expressed only at $-\mathrm{N}$ condition and have a central role only in one network (Table S9). Considering the specific genes, for durum wheat one of them was expressed in both condition, two only at $-\mathrm{N}$ and four at $+\mathrm{N}$, while in the case of emmer all the six DEGs were expressed at $-\mathrm{N}$ condition.

\section{Discussion}

In a preceding work, we found that emmer and durum wheat showed contrasting phenotypic responses associated to $\mathrm{N}$ starvation [37]. Here, we present the results of gene expression and metabolites levels of emmer and durum wheat using two representative genotypes which were part of the previous investigation. Indeed, a striking result showed by our study is the major differences in the response to $\mathrm{N}$ starvation between our emmer and durum wheat genotypes based on their gene expression and metabolite levels. Emmer responded to the stress condition by slowing down all the metabolic functions, probably limiting his energy expenditure. On the contrary, durum wheat responded to the stress condition by activating a much larger number of genes (e.g., triggering more defense responsive pathways) and mechanisms resulting in an accumulation of metabolites in the investigated tissues (leaves) most likely associated to a metabolic imbalance. Differences in plant growth were observed in both genotypes under nitrogen starvation also considering the morphological trait. In fact, the significant variations were mainly observed in the aerial part for durum wheat and in the below ground part concerning the emmer genotype in agreement to the results reported by Gioia et al. [37] by comparing representative sets of genotypes from the different subspecies.

Durum wheat responded to $\mathrm{N}$ starvation with a much higher number of DEGs upregulated. Some of these genes, directly involved in $\mathrm{N}$ metabolism, were differentially expressed exclusively in durum wheat (i.e., NR (upregulated), GS and GDH (downregulated)). In addition, the results of gene enrichment analysis indicate that emmer and durum wheat adapt to nitrogen starvation by a reprogramming of transcription. Transcription factors are important for controlling the expression of other genes in plant exposed 
to limited $\mathrm{N}$ condition or in complete starvation $[12,15,17]$ and, accordingly, our results showed as the regulation of transcripts was highly different and, in some case, with an opposite trend between emmer and durum wheat. In addition, some GO categories were only enriched for the DEGs in durum wheat, such as: the cellular amino acids, oxoacid or organic acids metabolism which were also highlighted by Huang et al. [38] in their study on the transcriptomic evaluation in response to the imbalance of carbon: nitrogen ratio in rice seedling.

Moreover, the levels of metabolites showed significant differences in response to the $\mathrm{N}$ starvation in both emmer and durum wheat. In general, in stressed conditions a reduction in plant growth and photosynthesis is expected [39] and, consequently, this should lead to a decrease in monosaccharides content. Nevertheless, an increase in the starch and soluble sugars content was reported in the shoot of Arabidopsis thaliana under N starvation [12]. Accordingly, an increase of total sugars in both genotypes was observed, with a pronounced effect in durum wheat (which also showed a significant decrease of photosynthetic efficiency) [12].

Consistently to the differences observed at transcriptomic level, the content of amino acids, under $\mathrm{N}$ starvation was lower in emmer (fold change $=-2.7$ ), while in durum wheat a higher accumulation (fold change $=1.7$ ) of these metabolites was observed. Tschoep et al. [40] showed that when Arabidopsis plants were grown under continuous N limitation, the total amino acids levels were found to be higher than under high $\mathrm{N}$ condition due to a metabolic imbalance. The results obtained in our conditions suggest a reduced use of amino acids for protein synthesis and growth in durum wheat that links with the reduction of photosynthetic activity under $\mathrm{N}$ starvation. On the other hand, the lower accumulation in emmer may indicate an earlier phase of the $\mathrm{N}$ starvation syndrome which could result in a drastically reduced, but still efficient, metabolism.

In this sense, it is also important to discuss carefully the behaviors of both glutamic acid and GABA, both altered in response to the $\mathrm{N}$ starvation condition in emmer and durum wheat. GABA is synthesized mainly from glutamate, closely associated with the TCA cycle, and having a signaling role [28,41,42]. Two studies have suggested a signaling role of GABA during the nitrate uptake in both Brassica napus root [43] and Arabidopsis thaliana [44]. Moreover, Sulieman [45] reported the important role of GABA in increasing of the efficiency of symbiotic $\mathrm{N}_{2}$ fixation in legumes. Michaeli and Fromm [46], proposed that the metabolic and signaling functions of GABA has been evolved to be functionally entwined under nutrient starvation. Thus, it seems that GABA levels increase during plant nutrient starvation and energetically demanding stresses [47], aspect that could be supported, from our data, by the negative correlation between the SPAD values (indicating reduced chlorophyll content) and the GABA content in durum wheat $(\mathrm{r}=-0.86$; $p=0.0061)$. On the other hand, Forde and Lea [48] reported the possible long-distance signaling role of glutamate between shoot and root as part of a network of $\mathrm{N}$ signaling pathways that enable the plant to monitor and adapt to changes in $\mathrm{N}$ status. In their model, when the shoot-derived glutamate arrive at the root tip, is sensed by plasma membrane glutamate receptors enabling meristematic activity in the root tip to respond to changes in the N/C status of the shoot. In our study, the positive correlation in emmer between shoot glutamate and SRL $(r=0.97 ; p=0.0001)$ could support this suggestion. In addition, the increase of the root morphological parameters in emmer under $\mathrm{N}$ starvation could be also sustained by a greater remobilization of the amino acids from the shoot to the root. The key role of GABA and glutamate is also supported by the results of the correlation-based network analysis integrating the information from both metabolites and transcripts. Indeed, durum wheat-specific network was characterized by the role of GABA that was associated to many (479) DEGs while in emmer-specific networks the glutamate was highly connected to many (201) other DEGs. This finding, on one hand, underlies their important role as signaling metabolites in stress conditions as those occurring during nitrogen starvation and, on the other hand, it may suggest the occurrence of two contrasting 
strategies based on GABA and glutamate signaling that appear associated with shoot and root growth, respectively.

The genotype-specific networks of the two tetraploid wheats showed different structures. Overall, only one DEG (downregulated) common to both emmer and durum wheat showed a central role in the corresponding networks (i.e., Stress Enhanced Protein 2-[SEP2]) which is a light-inducible gene as showed in Arabidopsis thaliana and rice [49]. A previous work reported that the regulation of SEP gene expression by light stress is very specific while other physiological stresses-such as cold, heat, wounding, desiccation, salt, or oxidative stress - did not promote accumulation of SEP transcripts indicating that they were not triggered by photooxidative damage itself [50]. Therefore, based on our results we can speculate that SEP2 is inducible by both light and N starvation.

Among the genes having a central role in the durum wheat-specific network, there were some transcription factors (i.e., DEAD-box ATP-dependent RNA helicase 3[DEAD-box RH3] and the MIKC-type MADS-box transcription factor) as well as some stress responsive genes (i.e., peroxidase and protein detoxification). For example, as well documented, the DEAD-box RNA helicases are involved in RNA metabolism and have important roles in diverse cellular functions (e.g., plant growth and development, and in response to biotic and abiotic stresses [51-54]). Recently, Gu et al. [55] demonstrated the relevant role of the chloroplast DEAD-box $\mathrm{RH} 3$ on the growth and stress response in Arabidopsis thaliana. Interestingly, it is reported that in bread wheat the MIKC-type MADS-box TFs have key roles in plant growth [56,57]; however, even if one of these transcription factors (Traes_5AL_13E2DEC48) was a central node in the durum wheat-specific network, it was downregulated under $\mathrm{N}$ starvation in comparison to the optimal $\mathrm{N}$ condition.

Moreover, several studies reported that in wheat, grown in either in field or greenhouse conditions, activities of many enzymes in the antioxidant defense system (i.e., SOD, CAT, GPX, GR, Prx, and LOX) are altered to control the oxidative stress induced by other factors and to maintain the balance between ROS production and detoxification which avoid potential damage to cellular components, metabolism, development and growth system [58,59] and reference therein. For example, Kumar et al. [60] reported an increase of SOD transcript in wheat in response to heat shock treatment that may indicate greater tolerance to environmental stresses. Also, in this study, many important genes related to the antioxidant defense system were upregulated in both genotypes but with a ratio of 1:2 between our emmer and durum wheat.

The upregulation of genes involved in the defense-system and the increase in the content of metabolites under starvation observed in durum wheat suggest that a possible mechanism of response to the starvation may be linked to the autophagy. This process is inducible in different and multiple stress condition or development stages, and it is defined as a non-specific degradation process for the recycling of intracellular material that might be used as building blocks to temporarily overcome the absence of nutrients (e.g., nitrogen) [61,62]. Nutrient limitation also increases ROS production, which in turn may stimulate autophagy functioning as signaling molecules as suggested by Liu et al. [63]. Taken together, these findings indicate that the absence of nutrients is a primary signal leading to autophagy activation in eukaryotes, but this stress signal is tightly associated with the production and accumulation of ROS. Because the chloroplasts are primary source of ROS in plants, their degradation through autophagic processes may be highly possible as also reported under carbon-limited conditions [64].

To face environmental constrains, according to the plant-life history (the distribution of resources between growth, reproduction, and defense), plants can combine acclimation mechanisms from different strategies defined as escape or resistance [39] and references therein. In this sense, probably, emmer as adaptive strategy to N starvation relied mainly on the below-ground part while the durum wheat reacts on the up-ground part. Indeed, the responses of emmer appear more plastic with enhanced activation of root growth under $\mathrm{N}$ starvation then durum wheat which trigger to maintain growth rate even in absence of available N. Although our experiment did not analyze the transcriptomic and/or 
metabolomics responses of the roots, and the proposed adaptative strategy deserves further investigation, it provides important information with respect to differential response on the level of gene and metabolites involving in the efforts of this crop to retain homeostasis under nutrient stress conditions.

A future perspective would be to identify and characterize the different mechanisms of signaling and response to limited nitrogen soil availability in different tetraploid wheats. This could be exploited to define innovative genetic strategies to develop smart varieties able to cope with low nitrogen in harsh and unpredictable environments as could be expected because of climate changes.

\section{Materials and Methods}

\subsection{Plant Material and Experimental Design}

Here we considered two genotypes of Triticum turgidum which showed many contrasting traits (including differences in grain yield (GY), heading date (HD), plant height $(\mathrm{PH})$, test weight (TW), thousand kernel weight (TKW), protein content (PC), yellow index (YI), gluten index (GI), roots and shoot morphological parameters [65-67]): one emmer (T. turgidum ssp. dicoccum) named 'Molise Selezione Colli', a pure line selected from a local population, and one modern durum wheat cultivar (T. turgidum ssp. durum) named 'Simeto' (derived from Capeiti/Valnova), released in ltaly in 1988. Both genotypes were previously purified by two cycles of single seed descent (SSD). The samples of this study were part of a larger four-week-long experiment conducted in 2012 under contrasting Nitrogen conditions as reported in Gioia et al. [16]. Briefly, the full experiment included 12 genotypes for each tetraploid wheat subspecies (T. turgidum ssp. dicoccoides (wild emmer), ssp. dicoccum (emmer), and ssp. durum (durum wheat)) and the resulting 36 genotypes were grown under $\mathrm{N}$ starvation $(-\mathrm{N})$ and $\mathrm{N}$ optimal $(+\mathrm{N})$ conditions with two replicates per genotype in two subsequent growing conditions. Thus, for each nitrogen treatment, genotypes were replicated four times using two plants per replicate with overall eight plants per genotype per treatment. Each rhizobox contained two different genotypes of the same subspecie, each represented by two plants arranged to avoid contacts between roots of different genotypes.

This means that the two genotypes considered here were grown in four different rhizoboxes for each $\mathrm{N}$ condition.

Before sowing, for each genotype, grains of uniform size were visually selected, surface sterilized $(1 \% \mathrm{NaClO}(w / v)$ for $15 \mathrm{~min})$, pre-germinated and then transplanted into the soil-filled rhizoboxes which were placed into the automated GROWSCREEN-Rhizo phenotyping system available at the Institute of Biosciences and Geosciences (IBG-2): Plant Sciences Institute, Forschungszentrum Julich GmbH, Germany (50 $54^{\prime} 36^{\prime \prime} \mathrm{N}, 06^{\circ} 24^{\prime} 49^{\prime \prime} \mathrm{E}$ ). The soil used to fill the rhizoboxes was a 'Typ 0' manually sieved peat soil (Nullerde Einheitserde; Balster Einheitserdewerk, Frondenberg, Germany), which provided low nutrient availability (e.g., available ammonium nitrogen and nitrate nitrogen concentrations of $<1.0$, and $<1.0 \mathrm{mg} \mathrm{L}^{-1}$, respectively). All plants were watered regularly twice a day with $400 \mathrm{~mL}$ of tap water and supplied three times per week with $200 \mathrm{~mL}$ of modified Hoagland solution [68] with or without added nitrogen (for the starvation condition $\mathrm{KNO}_{3}$ and $\mathrm{Ca}\left(\mathrm{NO}_{3}\right)_{2}$ were replaced by $\mathrm{K}_{2} \mathrm{SO}_{4}$ and $\mathrm{CaCl}_{2} \cdot 6\left(\mathrm{H}_{2} \mathrm{O}\right)$, respectively). The experiments were carried out under natural lighting in a greenhouse, with the air temperature kept between 18 and $24{ }^{\circ} \mathrm{C}$, and the relative humidity between $40 \%$ and $60 \%$. For more details concerning the experiment and growth conditions see Gioia et al. [16]. At the end of the experiment, for each replicate, leaves of the two plants were pooled and immediately frozen in liquid nitrogen to obtain leaves tissues for RNA and metabolites extraction.

\subsection{Phenotypic Traits}

The following traits were scored for both genotypes: the total leaf area (TLA), the total number of leaves (TLN), and the principal parameters of the root system architecture, such as: visible primary root length (PRL), visible lateral root length (LRL), total root 
length (TRL) of all visible roots, root system depth (RSD), and root system width (RSW). At the end of the experiment, at 28 days after sowing (DAS) (Zadoks stage 14-18 for optimal N; Zadoks stage 12-14 for N starvation; [69]), the chlorophyll content (SPAD units) was estimated with a SPAD-502 chlorophyll meter (Minolta Corp., Ramsey, NJ, USA). In addition, wheat plants were harvested to determine the shoot fresh weight (SFW) and the root biomass (root dry weight; RDW) after a careful washing and oven drying. More details of each determination were reported in Gioia et al. [16].

\subsection{Transcriptomic Analysis}

Measures of $100 \mathrm{mg}$ of frozen ground tissue (leaves) of each replicate (the two genotypes were replicates four times using two plants per replicate for each $\mathrm{N}$ treatment) were used for RNA extraction using the Spectrum Plant Total RNA kit (SigmaAldrich,Milan,Italy) and then treated with RNase-Free DNase by the On-Column DNase I Digestion Set (Sigma-Aldrich, Milan,Italy). RNA integrity and purity were assessed in Bioanalyzer 2100 (Agilent Bonsai Technologies) using agarose gel. For the subsequent analysis only RNA samples with integrity greater than 8.0 were used.

Library construction and RNA sequencing were carried out at the Montpellier Genomix (http:/ / www.mgx.cnrs.fr, 05 March 2018) sequencing facility using the Illumina mRNASeq technology. Libraries quantification, RNA-Seq data filtering and processing used in this study were essentially as those described previously by David et al. [70]. The bread wheat chromosome survey sequence for the cv. Chinese Spring (http:/ / plants.ensembl. org/triticum_aestivum, 12 March 2018) generated by the International Wheat Genome Sequencing Consortium (IWGSC) was used as the reference assembly.

The Biomart package of EnsEMBL were used to acquire the transcripts, and the physical genomic location of the 66,307 genes was predicted from the IWGSC on the genome A and B (Ensembl release 22, http:/ / plants.ensembl.org/biomart/martview/, 10 April 2018). Since these sequences were obtained by separately sequencing each bread wheat chromosome arm, the bread wheat reference helped to distinguish paralogous durum wheat copies.

RNA-Seq reads were mapped on the bread wheat reference transcriptome using BWA [71] while allowing three errors $(-\mathrm{n} 3$ in the alignment step). BWA, despite not being designed for RNA sequence alignment, was chosen because of the lower memory consumption [72] and comparable results obtained with other methods [73,74]. Picard tools (http:/ / picard.sourceforge.net, 10 April 2018) were used to remove PCR and optical duplicates. Rough read counts were computed at all sites for each individual using the idxstats function of the Samtools.

\subsection{Metabolite Profiling}

After collection, part of the frozen leaves of each replicate were freeze-dried and successively milled using a Pulverisette 7 Planetary Micro Mill (Classic Line, Fritsch GmbH Milling and Sizing, Idar-Oberstain, Germany) with an agate jar and balls, and stored at $-20{ }^{\circ} \mathrm{C}$ until analysis.

A total of $30 \mathrm{mg}$ dry weight $(\mathrm{dw})$ of each replicate was used for the extraction, derivatization and analysis by gas chromatography-mass spectrometry (GC-MS) of the polar and non-polar metabolites, as previously described [75]. Metabolites were identified by comparing the mass spectrometry data with those of a custom library obtained with reference compounds and with those of the National Institute of Standards and Technology (NIST 2011) database. The chromatograms and mass spectra evaluation and quantification were performed using the Mass Hunter software.

The standards and all the chemicals used were HPLC grade (Sigma-Aldrich Chemical Co., Deisenhofen, Germany). 


\subsection{Statistical Analysis}

Analysis of variance (ANOVA) was carried out with respect to each morphological trait and metabolite detected in the shoot of emmer and durum wheat lines considered. Mean discrimination between emmer and durum was performed applying Tukey's test and statistically significant differences were determined at the significance level of $\alpha=0.05$. Statistical analysis of the data was performed using the JMP software (SAS Institute Inc., Cary, NC, USA version 8).

\subsection{Bioinformatics Analysis and Network Construction \\ 4.6.1. Data Preprocessing}

First, genes for which the count per million (cpm) for a single sample was smaller than one and the sum of cpms across all samples was smaller than the total number of samples were filtered out. Raw counts were first normalized using trimmed mean of M-values normalization method ( $\mathrm{R}$ package edgeR) [76] and then voom normalized using the $\mathrm{R}$ package limma [77].

\subsubsection{Analysis of Differential Expression}

Analysis of differential expression was conducted on the data after data preprocessing. DEGs were determined between $\mathrm{N}$ starvation and a control with optimal $\mathrm{N}$ level for the following scenarios: (i) for each genotype and (ii) between the two genotypes. For the two scenarios, a linear model was employed to determine differential behavior. To this end, we applied the R package limma [77].

\subsubsection{GO Enrichment Analysis}

Annotations were extracted from EnsemblPlants [78] (http:/ /plants.ensembl.org/ biomart/martview/2ace56daacae40bad4af00cc25d51e4f, accessed on 2 May 2019) and agriGO (http:/ / bioinfo.cau.edu.cn/agriGO/download.php, accessed on 2 May 2019) [79]. We used hypergeometric test [80] to identify enriched terms in the list of DEGs. The cut-off value for significance level was considered as 0.05 after FDR correction.

\subsubsection{Network Analysis}

Co-expression networks were extracted by applying Pearson correlation on all pairs of data profiles, resulting in a similarity matrix $S_{m \times m}$. We then build a network $G=(V, E)$ with $m$ nodes, corresponding to the DEGs; there is an edge between two nodes $i, j \in V(G)$ if and only if the entry $s_{\mathrm{ij}}$ of $\mathrm{S}$ is significant at the level of 0.05 , after FDR correction.

Co-expression networks are separately reconstructed for the data from each genotype (i.e., Molise Sel. Colli and Simeto), by identifying significant correlation coefficients between each pair of genes in the network ( $p$ value $<0.05$, FDR corrected). For each pair of genes in the network, the Fisher Z-score test is used to assess the significance of the difference between the correlation coefficients obtained from emmer and durum wheat data. The edge between a pair of genes is referred to as a 'significantly different edge' if the obtained $p$-value from Fisher Z-score test is smaller than 0.05 after FDR correction. The degree and the betweenness centralities of all nodes (i.e., DEGs) in co-expression networks and the differential networks were calculated using the $R$ package igraph [81]. The same analysis was repeated for metabolite data, and integration of metabolite and transcript data; however, the entire metabolite profiles were used in these cases.

To find the nodes (i.e., genes and metabolites) which capture the differences between the two genotypes, we scored the nodes by the number of correlations of value larger than $\tau$ ( $\tau$ was considered to be 0.6 and 0.8 ) present in emmer but not in durum wheat co-expression network and vice versa. 
Supplementary Materials: The following are available online at https: / www.mdpi.com/article / 10.3390 /ijms22094790/s1, Table S1. Reads and mapping results. Table S2. Differentially expressed genes in common or specific in emmer (cv. Molise Sel. Colli) and in durum wheat (cv. Simeto) under nitrogen starvation. Key genes involved in nitrogen metabolism, carbon metabolism, transporters, transcription factors, kinases, and stress-related genes are reported. In blue are represented DEGs up regulated and in red DEGs down regulated. Table S3. Number of DEGs (up-/downregulated) under two N conditions, enriched GO terms before and after FDR correction in emmer (Molise Sel. Colli), durum wheat (Simeto), and in total. Table S4. Most significant GO categories in emmer (Molise Sel. Colli) and durum wheat (Simeto). Table S5. ANOVA for each individual metabolite, relating to their content in the leaves of emmer and durum wheat grown under starvation and optimal $\mathrm{N}$ conditions. Table S6. Number of edges between central DEGs genes and significantly behaved metabolites under the two $\mathrm{N}$ conditions. For each metabolite was highlight in bold the higher number of edges. Table S7. Putative functions of common DEGs in both tetraploid wheats with central roles in either of emmer-specific and durum wheat-specific networks. Table S8. Putative function of DEGs specific to each of the tetraploid wheats with central roles in either of emmer-specific and durum wheat-specific networks. Table S9. DEGs of networks affected by environment. Figure S1. Position of down- (red) and upregulated (blue) DEGs in emmer (Molise Sel. Colli) and durum wheat (Simeto) on the physical map. Central DEGs in the transcript-metabolite correlation networks were shown by triangles. Figure S2. (A) Total DEGs between $-\mathrm{N},+\mathrm{N}$ and common shared by durum wheat and emmer, (B) Total DEGs between $-\mathrm{N},+\mathrm{N}$ and specific of durum wheat, (C) Total DEGs between $-\mathrm{N},+\mathrm{N}$ and specific of emmer.

Author Contributions: R.B. and R.P. conceived and designed the study. T.G. and F.F. carried out the experiments and performed the morphological analysis; R.B. and F.M.N. performed the metabolite analyses. Y.H. and J.L.D. performed the RNA seq analysis; N.O. and Z.N. performed the bioinformatics and network analyses. R.B., R.P., N.O. and Z.N. analyzed data and wrote the paper. U.S., N.P. and P.D.V. reviewed the manuscript. All authors have read and agreed to the published version of the manuscript.

Funding: This research received no external funding.

Institutional Review Board Statement: Not applicable.

Informed Consent Statement: Not applicable.

Data Availability Statement: Data is contained within the article Data citation.

Acknowledgments: The authors are thankful to Assaf Distelfeld for providing genomic information and for a critical reading of the manuscript. T.G. thanks the SIR-MIUR grant number [RBSI14SJ81]. Z.N. and N.O. are funded by the European Union's Horizon 2020 research and innovation program, project PlantaSYST SGA-CSA No. 739582. RP thanks the Università Politecnica delle Marche financial support. This work was supported by the PON a3 PlASS Project. PlASS -Platform for Agrofood Science and Safety and by the Transnational Access capacities of the European Plant Phenotyping Network (EPPN, grant agreement no. 284443) funded by the FP7 Research Infrastructures Program of the European Union.

Conflicts of Interest: The authors declare that the research was conducted in the absence of any commercial or financial relationships that could be construed as a potential conflict of interest.

\section{References}

1. Lea, P.J.; Azevedo, R.A. Nitrogen use efficency. 1. Uptake of nitrogen from the soil. Ann. Appl. Biol. 2006, 149, 243-247. [CrossRef]

2. Miller, A.J.; Fan, X.; Orsel, M.; Smith, S.J.; Wells, D.M. Nitrate transport and signalling. J. Exp. Bot. 2007, 58, 2297-2306. [CrossRef]

3. Obata, T.; Fernie, A.R. The use of metabolomics to dissect plant responses to abiotic stresses. Cell. Mol. Life Sci. 2012, 69, 3225-3243. [CrossRef]

4. Raun, W.R.; Johnson, G.V. Improving Nitrogen Use Efficiency for Cereal Production. Agron. J. 1999, 91, 357-363. [CrossRef]

5. Cassman, K.G.; Dobermann, A.; Walters, D.T.; Yang, H. Meeting cereal demand while protecting natural resources and improving environmental quality. Annu. Rev. Environ. Resour. 2003, 28, 315-358. [CrossRef]

6. Ayadi, S.; Karmous, C.; Hammami, Z.; Trifa, Y.; Rezgui, S. Variation of Durum Wheat Yield and Nitrogen Use Efficiency under Mediterranean Rainfed Environment. Intl. J. Agric. Crop Sci. 2014, 7, 693-699. [CrossRef] 
7. Ruisi, P.; Frangipane, B.; Amato, G.; Frenda, A.S.; Plaia, A.; Giambalvo, D.; Saia, S. Nitrogen uptake and nitrogen fertilizer recovery in old and modern wheat genotypes grown in the presence or absence of interspecific competition. Front. Plant Sci. 2015, 6, 185. [CrossRef] [PubMed]

8. Nesbitt, M.; Samuel, D. Wheat domestication: Archaeobotanical evidence. Science 1998, 279, 1431. [CrossRef]

9. Tanno, K.I.; Willcox, G. How fast was wild wheat domesticated? Science 2006, 311, 1886. [CrossRef]

10. Luo, M.-C.; Yang, Z.-L.; You, F.M.; Kawahara, T.; Waines, J.G.; Dvorak, J. The structure of wild and domesticated emmer wheat populations, gene flow between them, and the site of emmer domestication. Theor. Appl. Genet. 2007, 114, 947-959. [CrossRef]

11. Nevo, E. Evolution of wild emmer wheat and crop improvement. J. Syst. Evol. 2014, 52, 673-696. [CrossRef]

12. Godfray, H.C.J.; Beddington, J.R.; Crute, I.R.; Haddad, L.; Lawrence, D.; Muir, J.F.; Pretty, J.; Robinson, S.; Thomas, S.M.; Toulmin, C. Food Security: The Challenge of Feeding 9 Billion People. Science 2010, 327, 812-818. [CrossRef] [PubMed]

13. Kant, S.; Bi, Y.-M.; Rothstein, S.J. Understanding plant response to nitrogen limitation for the improvement of crop nitrogen use efficiency. J. Exp. Bot. 2010, 62, 1499-1509. [CrossRef]

14. Xu, G.; Fan, X.; Miller, A.J. Plant Nitrogen Assimilation and Use Efficiency. Annu. Rev. Plant Biol. 2012, 63, 153-182. [CrossRef]

15. Hawkesford, M.J. Genetic variation in traits for nitrogen use efficiency in wheat. J. Exp. Bot. 2017, 68, 2627-2632. [CrossRef]

16. Gioia, T.; Nagel, K.A.; Beleggia, R.; Fragasso, M.; Ficco, D.B.M.; Pieruschka, R.; De Vita, P.; Fiorani, F.; Papa, R. Impact of domestication on the phenotypic architecture of durum wheat under contrasting nitrogen fertilization. J. Exp. Bot. 2015, 66, 5519-5530. [CrossRef]

17. Krapp, A.; Berthomé, R.; Orsel, M.; Mercey-Boutet, S.; Yu, A.; Castaings, L.; Elftieh, S.; Major, H.; Renou, J.-P.; DanielVedele, F. Arabidopsis roots show distinct temporal adaptation patterns towards nitrogen starvation. Plant Physiol. 2011, 157, 1255-1282. [CrossRef]

18. Humbert, S.; Subedi, S.; Cohn, J.; Zeng, B.; Bi, Y.-M.; Chen, X.; Zhu, T.; McNicholas, P.D.; Rothstein, S.J. Genome-wide expression profiling of maize in response to individual and combined water and nitrogen stresses. BMC Genom. 2013, 14, 3. [CrossRef]

19. Simons, M.; Saha, R.; Guillard, L.; Clément, G.; Armengaud, P.; Cañas, R.; Maranas, C.D.; Lea, P.J.; Hirel, B. Nitrogen-use efficiency in maize (Zea mays L.): From 'omics' studies to metabolic modelling. J. Exp. Bot. 2014, 65, 5657-5671. [CrossRef] [PubMed]

20. Curci, P.L.; Cigliano, R.A.; Zuluaga, D.L.; Janni, M.; Sanseverino, W.; Sonnante, G. Transcriptomic response of durum wheat to nitrogen starvation. Sci. Rep. 2017, 7, 1-14. [CrossRef]

21. Zuluaga, D.L.; De Paola, D.; Janni, M.; Curci, P.L.; Sonnante, G. Durum wheat miRNAs in response to nitrogen starvation at the grain filling stage. PLoS ONE 2017, 12, e0183253. [CrossRef]

22. Yang, J.; Chen, X.; Zhu, C.; Peng, X.; He, X.; Fu, J.; Ouyang, L.; Bian, J.; Hu, L.; Sun, X.; et al. RNA-seq reveals differentially expressed genes of rice (Oryza sativa) spikelet in response to temperature interacting with nitrogen at meiosis stage. BMC Genom. 2015, 16, 959. [CrossRef]

23. Gelli, M.; Duo, Y.; Konda, A.R.; Zhang, C.; Holding, D.; Dweikat, I. Identification of differentially expressed genes between sorghum genotypes with contrasting nitrogen stress tolerance by genome-wide transcriptional profiling. BMC Genom. 2014, 15, 179. [CrossRef] [PubMed]

24. Guo, T.; Xuan, H.; Yang, Y.; Wang, L.; Wei, L.; Wang, Y.; Kang, G. Transcription Analysis of Genes Encoding the Wheat Root Transporter NRT1 and NRT2 Families During Nitrogen Starvation. J. Plant Growth Regul. 2014, 33, 837-848. [CrossRef]

25. Chen, R.; Tian, M.; Wu, X.; Huang, Y. Differential global gene expression changes in response to low nitrogen stress in two maize inbred lines with contrasting low nitrogen tolerance. Genes Genom. 2011, 33, 491-497. [CrossRef]

26. Hao, Q.N.; Zhou, X.A.; Sha, A.H.; Wang, C.; Zhou, R.; Chen, S.L. Identification of genes associated with nitrogen-use efficiency by genome-wide transcriptional analysis of two soybean genotypes. BMC Genom. 2011, 12, 525. [CrossRef] [PubMed]

27. Scheible, W.-R.; Morcuende, R.; Czechowski, T.; Fritz, C.; Osuna, D.; Palacios-Rojas, N.; Schindelasch, D.; Thimm, O.; Udvardi, M.K.; Stitt, M. Genome-Wide Reprogramming of Primary and Secondary Metabolism, Protein Synthesis, Cellular Growth Processes, and the Regulatory Infrastructure of Arabidopsis in Response to Nitrogen. Plant Physiol. 2004, 136, 2483-2499. [CrossRef]

28. Amiour, N.; Imbaud, S.; Clément, G.; Agier, N.; Zivy, M.; Balot, B.; Balliau, T.; Armengaud, P.; Quilleré, I.; Cañas, R.; et al. The use of metabolomics integrated with transcriptomic and proteomic studies for identifying key steps involved in the control of nitrogen metabolism in crops such as maize. J. Exp. Bot. 2012, 63, 5017-5033. [CrossRef]

29. Bielecka, M.; Watanabe, M.; Morcuende, R.; Scheible, W.-R.; Hawkesford, M.J.; Hesse, H.; Hoefgen, R. Transcriptome and metabolome analysis of plant sulfate starvation and resupply provides novel information on transcriptional regulation of metabolism associated with sulfur, nitrogen and phosphorus nutritional responses in Arabidopsis. Front. Plant Sci. 2015 , 5, 805. [CrossRef] [PubMed]

30. Vicente, R.; Pérez, P.; Martínez-Carrasco, R.; Feil, R.; Lunn, J.E.; Watanabe, M.; Arrivault, S.; Stitt, M.; Hoefgen, R.; Morcuende, R. Metabolic and Transcriptional Analysis of Durum Wheat Responses to Elevated $\mathrm{CO}_{2}$ at Low and High Nitrate Supply. Plant Cell Physiol. 2016, 57, 2133-2146. [CrossRef]

31. Yu, C.; Zhao, X.; Qi, G.; Bai, Z.; Wang, Y.; Wang, S.; Ma, Y.; Liu, Q.; Shumin, W.; Zhou, G. Integrated analysis of transcriptome and metabolites reveals an essential role of metabolic flux in starch accumulation under nitrogen starvation in duckweed. Biotechnol. Biofuels 2017, 10, 1-14. [CrossRef]

32. Hirai, M.Y.; Klein, M.; Fujikawa, Y.; Yano, M.; Goodenowe, D.B.; Yamazaki, Y.; Kanaya, S.; Nakamura, Y.; Kitayama, M.; Suzuki, H.; et al. Elucidation of Gene-to-Gene and Metabolite-to-Gene Networks inArabidopsis by Integration of Metabolomics andTranscriptomics*. J. Biol. Chem. 2005, 280, 25590-25595. [CrossRef] 
33. Caldana, C.; Degenkolbe, T.; Cuadros-Inostroza, A.; Klie, S.; Sulpice, R.; Leisse, A.; Steinhauser, D.; Fernie, A.R.; Willmitzer, L.; Hannah, M.A. High-density kinetic analysis of the metabolomic and transcriptomic response of Arabidopsis to eight environmental conditions. Plant J. 2011, 67, 869-884. [CrossRef] [PubMed]

34. Toubiana, D.; Fernie, A.R.; Nikoloski, Z.; Fait, A. Network analysis: Tackling complex data to study plant metabolism. Trends Biotechnol. 2013, 31, 29-36. [CrossRef]

35. Toubiana, D.; Xue, W.; Zhang, N.; Kremling, K.; Gur, A.; Pilosof, S.; Gibon, Y.; Stitt, M.; Buckler, E.S.; Fernie, A.R.; et al. Correlation-Based Network Analysis of Metabolite and Enzyme Profiles Reveals a Role of Citrate Biosynthesis in Modulating N and C Metabolism in Zea mays. Front. Plant Sci. 2016, 7, 1022. [CrossRef]

36. Beleggia, R.; Rau, D.; Laidò, G.; Platani, C.; Nigro, F.; Fragasso, M.; De Vita, P.; Scossa, F.; Fernie, A.R.; Nikoloski, Z.; et al. Evolutionary Metabolomics Reveals Domestication-Associated Changes in Tetraploid Wheat Kernels. Mol. Biol. Evol. 2016, 33, 1740-1753. [CrossRef] [PubMed]

37. Russo, M.A.; Ficco, D.B.M.; Laidò, G.; Marone, D.; Papa, R.; Blanco, A.; Gadaleta, A.; De Vita, P.; Mastrangelo, A.M. A dense durum wheat T. dicoccum linkage map based on SNP markers for the study of seed morphology. Mol. Breed. 2014, 34, 1579-1597. [CrossRef]

38. Huang, A.; Sang, Y.; Sun, W.; Fu, Y.; Yang, Z. Transcriptomic Analysis of Responses to Imbalanced Carbon: Nitrogen Availabilities in Rice Seedlings. PLoS ONE 2016, 11, e0165732. [CrossRef]

39. Shaar-Moshe, L.; Hayouka, R.; Roessner, U.; Peleg, Z. Phenotypic and metabolic plasticity shapes life-history strategies under combinations of abiotic stresses. Plant Direct 2019, 3, e00113. [CrossRef] [PubMed]

40. Tschoep, H.; Gibon, Y.; Carillo, P.; Armengaud, P.; Szecowka, M.; Nunes-Nesi, A.; Fernie, A.R.; Koehl, K.; Stitt, M. Adjustment of growth and central metabolism to a mild but sustained nitrogen-limitation inArabidopsis. Plant Cell Environ. 2009, 32, 300-318. [CrossRef]

41. Bouché, N.; Fromm, H. GABA in plants: Just a metabolite? Trends Plant Sci. 2004, 9, 110-115. [CrossRef] [PubMed]

42. Fait, A.; Fromm, H.; Walter, D.; Galili, G.; Fernie, A.R. Highway or byway: The metabolic role of the GABA shunt in plants. Trends Plant Sci. 2008, 13, 14-19. [CrossRef]

43. Beuve, N.; Rispail, N.; Laine, P.; Cliquet, J.B.; Ourry, A.; Le Deunff, E. Putative role of g-aminobutyric acid (GABA) as a long-distance signal in up-regulation of nitrate uptake in Brassica napus L. Plant Cell Environ. 2004, 27, 1035-1046. [CrossRef]

44. Barbosa, J.M.; Singh, N.K.; Cherry, J.H.; Locy, R.D. Nitrate uptake and utilization is modulated by exogenous g-aminobutyric acid in Arabidopsis thaliana seedlings. Plant Physiol. Biochem. 2010, 48, 443-450. [CrossRef]

45. Sulieman, S. Does GABA increase the efficiency of symbiotic $\mathrm{N}_{2}$ fixation in legumes? Plant Sign. Behav. 2011, 6, 32-36. [CrossRef] [PubMed]

46. Michaeli, S.; Fromm, H. Closing the loop on the GABA shunt in plants: Are GABA metabolism and signaling entwined? Front. Plant Sci. 2015, 6, 419. [CrossRef]

47. Carillo, P. GABA Shunt in Durum Wheat. Front. Plant Sci. 2018, 9, 100. [CrossRef]

48. Forde, B.G.; Lea, P.J. Glutamate in plants: Metabolism, regulation, and signalling. J. Exp. Bot. 2007, 58, 2339-2358. [CrossRef]

49. Umate, P. Genome-wide analysis of the family of light-harvesting chlorophyll a/b-binding proteins in Arabidopsis and rice. Plant Signal. Behav. 2010, 5, 1537-1542. [CrossRef]

50. Heddad, M.; Adamska, I. Light stress-regulated two-helix proteins in Arabidopsis thaliana related to the chlorophyll a/b-binding gene family. PNAS 2000, 97, 3741-3746. [CrossRef]

51. Vashisht, A.A.; Tuteja, N. Stress responsive DEAD-box helicases: A new pathway to engineer plant stress tolerance. J. Photochem. Photobiol. B: Biol. 2006, 84, 150-160. [CrossRef] [PubMed]

52. Li, D.; Liu, H.; Zhang, H.; Wang, X.; Song, F. OsBIRH1, a DEAD-box RNA helicase with functions in modulating defence responses against pathogen infection and oxidative stress. J. Exp. Bot. 2008, 59, 2133-2146. [CrossRef]

53. Linder, P.; Jankowsky, E. From unwinding to clamping-The DEAD box RNA helicase family. Nat. Rev. Mol. Cell Biol. 2011, 12, 505-516. [CrossRef] [PubMed]

54. Zhu, M.; Chen, G.; Dong, T.; Wang, L.; Zhang, J.; Zhao, Z.; Hu, Z. SIDEAD31, a Putative DEAD-Box RNA Helicase Gene, Regulates Salt and Drought Tolerance and Stress-Related Genes in Tomato. PLoS ONE 2015, 10, e0133849. [CrossRef]

55. Gu, L.; Xu, T.; Lee, K.; Lee, K.H.; Kang, H. A chloroplast-localized DEAD-box RNA helicase AtRH3 is essential for intron splicing and plays an important role in the growth and stress response in Arabidopsis thaliana. Plant Physiol. Biochem. 2014, 82, 309-318. [CrossRef] [PubMed]

56. Ma, J.; Yang, Y.; Luo, W.; Yang, C.; Ding, P.; Liu, Y.; Qiao, L.; Chang, Z.; Geng, H.; Wang, P.; et al. Genome-wide identification and analysis of the MADS-box gene family in bread wheat (Triticum aestivum L.). PLoS ONE 2017, 12, e0181443. [CrossRef]

57. Li, Y.; Fu, X.; Zhao, M.; Zhang, W.; Li, B.; An, D.; Li, J.; Zhang, A.; Liu, R.; Liu, X. A Genome-wide View of Transcriptome Dynamics during Early Spike Development in Bread Wheat. Sci. Rep. 2018, 8, 1-16. [CrossRef] [PubMed]

58. Mittler, R.; Vanderauwera, S.; Gollery, M.; Van Breusegem, F. Reactive oxygen gene network of plants. Trends Plant Sci. 2004, 9 , 490-498. [CrossRef]

59. Caverzan, A.; Casassola, A.; Brammer, S.P. Antioxidant responses of wheat plants under stress. Genet. Mol. Biol. 2016, 39, 1-6. [CrossRef] 
60. Kumar, R.; Sharma, S.K.; Goswami, S.; Singh, K.; Gadpayle, K.A.; Singh, G.; Pathak, H.; Rai, R. Transcript profiling and biochemical characterization of mitochondrial superoxide dismutase (mtSOD) in wheat (Triticum aestivum) under different exogenous stresses. Aust. J. Crop Sci. 2013, 7, 414-424.

61. Liu, Y.; Bassham, D.C. Autophagy: Pathways for Self-Eating in Plant Cells. Annu. Rev. Plant Biol. 2012, 63, 215-237. [CrossRef]

62. Pérez-Pérez, M.E.; Lemaire, S.D.; Crespo, J.L. Reactive Oxygen Species and Autophagy in Plants and Algae. Plant Physiol. 2012, 160, 156-164. [CrossRef] [PubMed]

63. Liu, Y.; Xiong, Y.; Bassham, D.C. Autophagy is required for tolerance of drought and salt stress in plants. Autophagy 2009, 5, 954-963. [CrossRef] [PubMed]

64. Wada, S.; Ishida, H.; Izumi, M.; Yoshimoto, K.; Ohsumi, Y.; Mae, T.; Makino, A. Autophagy Plays a Role in Chloroplast Degradation during Senescence in Individually Darkened Leaves. Plant Physiol. 2009, 149, 885-893. [CrossRef] [PubMed]

65. De Vita, P.; Riefolo, C.; Codianni, P.; Cattivelli, L.; Fares, C. Agronomic and qualitative traits of T. turgidum ssp. dicoccum genotypes cultivated in Italy. Euphytica 2006, 150, 195-205. [CrossRef]

66. De Vita, P.; Mastrangelo, A.M.; Codianni, P.; Fornara, M. Bio-agronomic Evaluation of Old and Modern Wheat, Spelt and Emmer Genotypes for Low-input Farming in Mediterranean Environment. Ital. J. Agron. 2007, 2, 291-302. [CrossRef]

67. Iannucci, A.; Marone, D.; Russo, M.A.; De Vita, P.; Miullo, V.; Ferragonio, P.; Blanco, A.; Gadaleta, A.; Mastrangelo, A.M. Mapping QTL for Root and Shoot Morphological Traits in a Durum Wheat $\times$ T. dicoccum Segregating Population at Seedling Stage. Int. J. Genom. 2017, 2017, 1-17. [CrossRef]

68. Hoagland, D.R.; Arnon, D.I. The Water-Culture Method for Growing Plants without Soil. Circular 347; California Agricultural Experiment Station: Berkeley, CA, USA, 1950.

69. Zadoks, J.C.; Chang, T.T.; Konzak, C.F. A decimal code for the growth stages of cereals. Weed Res. 1974, 14, 415-421. [CrossRef]

70. David, J.; Holtz, Y.; Ranwez, V.; Santoni, S.; Sarah, G.; Ardisson, M.; Poux, G.; Choulet, F.; Genthon, C.; Roumet, P.; et al. Genotyping by sequencing transcriptomes in an evolutionary pre-breeding durum wheat population. Mol. Breed. 2014, 34, 1531-1548. [CrossRef]

71. Li, H.; Durbin, R. Fast and accurate short read alignment with Burrows-Wheeler transform. Bioinformatics 2009, 25, 1754-1760. [CrossRef]

72. Otto, C.; Stadler, P.F.; Hoffmann, S. Lacking alignments? The next-generation sequencing mapper segemehl revisited. Bioinformatics 2014, 30, 1837-1843. [CrossRef]

73. Costa-Silva, J.; Domingues, D.; Lopes, F.M. RNA-Seq differential expression analysis: An extended review and a software tool. PLoS ONE 2017, 12, e0190152. [CrossRef] [PubMed]

74. Schaarschmidt, S.; Fischer, A.; Zuther, E.; Hincha, D.K. Evaluation of Seven Different RNA-Seq Alignment Tools Based on Experimental Data from the Model Plant Arabidopsis thaliana. Int. J. Mol. Sci. 2020, 21, 1720. [CrossRef]

75. Beleggia, R.; Platani, C.; Nigro, F.; DeVita, P.; Cattivelli, L.; Papa, R. Effect of genotype, environment and genotype-by-environment interaction on metabolite profiling in durum wheat (Triticum durum Desf.) grain. J. Cereal Sci. 2013, 57, 183-192. [CrossRef]

76. Robinson, M.D.; McCarthy, D.J.; Smyth, G.K. edgeR: A Bioconductor package for differential expression analysis of digital gene expression data. Bioinformatics 2009, 26, 139-140. [CrossRef] [PubMed]

77. Smyth, G.K. Limma: Linear models for microarray data. In Bioinformatics and Computational Biology Solutions using R and Bioconductor; Gentleman, R., Carey, V., Dudoit, S., Irizarry, R., Huber, W., Eds.; Springer: New York, NY, USA, 2005 ; pp. 397-420.

78. Kinsella, R.J.; Kahari, A.; Haider, S.; Zamora, J.; Proctor, G.; Spudich, G.; Almeida-King, J.; Staines, D.; Derwent, P.; Kerhornou, A.; et al. Ensembl BioMarts: A hub for data retrieval across taxonomic space. Database 2011, 2011, bar030. [CrossRef] [PubMed]

79. Du, Z.; Zhou, X.; Ling, Y.; Zhang, Z.; Su, Z. agriGO: A GO analysis toolkit for the agricultural community. Nucleic Acids Res. 2010, 38, W64-W70. [CrossRef]

80. Kachitvichyanukul, V.; Schmeiser, B. Computer generation of hypergeometric random variatest. J. Stat. Comput. Simul. 1985, 22, 127-145. [CrossRef]

81. Csardi, G.; Nepusz, T. The igraph software package for complex network research. Inter. J. Complex Syst. 2006, 1695, 1-9. 